\title{
Clodronate in the management of different musculoskeletal conditions
}

\author{
Bruno FREDIANI ${ }^{1}$ *, Andrea GIUSTI ${ }^{2}$, Gerolamo BIANCHI ${ }^{3}$, Luca DALLE CARBONARE ${ }^{4}$, \\ Nazzarena MALAVOLTA ${ }^{5}$, Luca CANTARINI ${ }^{1}$, Gianantonio SAVIOLA ${ }^{6}$, Luigi MOLFETTA 7
}

'Department of Rheumatology, Osteoporosis and Osteoarticular Instrumental Diagnosis Center, University of Siena, Siena, Italy; ${ }^{2}$ Department of Ortho-Geriatrics, Rehabilitation and Stabilization, Frailty Area, Bone Clinic, Galliera Hospital, Genoa, Italy; '3Division of Rheumatology, Department of Locomotor System, ASL003, Genoa, Italy; ${ }^{4}$ Department of Medicine, University of Verona and Azienda Ospedaliera Universitaria Integrata Verona, Verona, Italy; ${ }^{5}$ Division of Rheumatology, Department of Cardiac Thoracic and Vascular Disease, University of Bologna, Bologna, Italy; 'Unit of Rheumatology and Rehabilitation, Salvatore Maugeri Foundation IRCCS, Castel Goffredo, Mantua, Italy; ${ }^{7}$ Division of Orthopedics and Traumatology, School of Medical and Pharmaceutical Science, DINOGMI Department, Section of Orthopedic Rehabilitation, University of Genoa, Genoa, Italy

Corresponding author: Bruno Frediani, Rheumatology Department, Osteoporosis and Osteoarticular Instrumental Diagnosis Center, University of Siena, Siena, Italy. E-mail: fredianibruno60@gmail.com

INTRODUCTION: Clodronic acid is a non-nitrogen-containing bisphosphonate largely used from some decades in the prevention and treatment of postmenopausal and secondary osteoporosis. In addition to antiresorptive activity, clodronate has shown anti-inflammatory and analgesic properties, and modulatory effects on bone and cartilage metabolism.

EVIDENCE ACQUISITION: A literature review has been conducted to characterize the mechanism of action of clodronate and to retrieve available evidence about the use of clodronate in primary and secondary osteoporosis, and its potential role in other musculoskeletal conditions and orthopedic surgery.

EVIDENCE SYNTHESIS: The efficacy and safety of the available clodronate formulations (oral, intravenous and intramuscular) in the prevention and treatment of postmenopausal and secondary osteoporosis, including corticosteroidnduced osteoporosis and bone mass loss secondary to endocrine, gastrointestinal and neoplastic diseases, have been demonstrated in a variety of clinical trials. The analgesic, anti-inflammatory, bone- and chondro-modulating properties of clodronate have allowed to expand its use in other musculoskeletal conditions to those currently approved. Clodronate has proven to be beneficial in the treatment of osteoarthritis of the knee and of the hand, in the management of complex regional pain syndrome, and in the peri- and postoperative phase in subjects undergoing arthroplasty.

CONCLUSIONS: The analysis of the available literature has shown that clodronate has relevant musculoskeletal effects beyond the antiresorptive activity. Further research is needed to better position clodronate therapy in the management of these conditions and to define the optimal formulation and dose regimen in any of the tested new indications.

(Cite this article as: Frediani B, Giusti A, Bianchi G, Dalle Carbonare L, Malavolta N, Cantarini L, et al. Clodronate in the management of different musculoskeletal conditions. Minerva Med 2018;109:300-25. DOI: 10.23736/S0026-4806.18.05688-4)

KEY WORDS: Clodronic acid - Osteoporosis - Osteoarthritis - Arthroplasty.

\section{Introduction} pausal osteoporosis and other metabolic bone diseases, such as bone loss induced by hormone suppressive therapy or glucocorticoids. Although the most important biological effect of BPs remains the reduction of bone remodeling through the inhibition of osteoclastic activity, there are important differences between individual BPs in the extra-skeletal immune-modulating and anti- 


\section{COPYRIGHT $^{\circledR} 2018$ EDIZIONI MINERVA MEDICA}

inflammatory effects that may expand the use of these therapeutic agents in clinical practice. ${ }^{1}$

Clodronate disodium is a non-nitrogen-containing BP (NNBP) that is available in Europe as oral, intravenous (i.v.), and intramuscular (i.m.) formulations for the treatment of hypercalcemia and/or osteolysis of malignancy, multiple myeloma, and for the prevention and treatment of post-menopausal osteoporosis. The effects of clodronate in the current indications are largely documented in a variety of clinical trials conducted over more than two decades. ${ }^{2}$ In recent years, there is accumulating evidence that clodronate may be effective in the treatment of other conditions, such as bone marrow edema and associated syndromes, erosive osteoarthritis of the hands, rheumatoid arthritis, as well in subjects undergoing prosthetic surgery. ${ }^{2,} 3$ The positive biological effects of clodronate in extra-skeletal conditions are not only related to its antiresorptive action, but to a more complex interaction between its pharmacological properties and the underlying pathophysiological mechanisms. Furthermore, the development of formulations suitable for intermittent dosing regimens has allowed to maintain the efficacy profile of clodronate and to tailor the therapeutic scheme to individual patients' need while improving adherence and persistency of treatment. ${ }^{1}$

This article reviews the recent insights on the mechanism of action of clodronate, the available literature on its consolidated use in the prevention and treatment of osteoporosis, and its potential use in other musculoskeletal conditions, including patients' undergoing orthopedic surgery.

\section{Evidence acquisition}

The search in literature has been performed with no time limitation using PubMed/Medline and searching for the term "clodronate" OR "clodronic acid" with no language restriction. All authors read the abstracts of all publications identified on the electronic databases, excluding only those that clearly did not meet the objectives of this review. Then, authors read the full-text articles of the selected publications and a consensus was made on those studies to be considered as suitable for citation.
The search has also been expanded to evaluate the documentation of the effects of other BPs (alendronate, risedronate, ibandronate, zoledronate, pamidronate, neridronate) in other non-approved indications for clodronate.

\section{Evidence synthesis}

\section{Clodronate: mechanism of action}

All BPs reduce osteoclast activity. NBPs (alendronate, risedronate, ibandronate, zoledronate, pamidronate, neridronate) specifically inhibit the enzyme farnesyl diphosphate synthase and block the prenylation of guanosine triphosphatebinding proteins that are essential for osteoclast function. ${ }^{4}$ In contrast, NNBPs (etidronate, clodronate) induce the production of toxic analogs of adenosine triphosphate (ATP) that accumulate intracellularly in osteoclasts, resulting in induction of osteoclast apoptosis. ${ }^{5}$ The antifracture effect of each BP is dependent on its ability to bind rapidly and with high affinity to the bone surface and on its antiresorptive potency.

BPs are analogs of inorganic pyrophosphate, and are composed of an enzyme-resistant phosphorus-carbon-phosphorus (P-C-P) structure able to adhere strongly to hydroxyapatite crystals. They have a relatively simple core structure, and the pharmacologic properties of each BP molecule depend on lateral chains, named R1 and R2. The P-C-P nucleus and R1 lateral chain are responsible for anchoring the drug to the bone mineral matrix, while R2 has biologic and therapeutic actions. The presence of a hydroxyl group in R1 markedly increases BPs affinity for the bone matrix, while the nitrogen atom in $\mathrm{R} 2$ is responsible for antiresorptive potency. 5

The therapeutic effect of BPs is mediated mainly by the inhibition of osteoclastic bone resorption, as demonstrated in bone biopsies, where fewer numbers of osteoclasts and lower bone erosion rates have been observed. ${ }^{4}$ Once embedded on the bone surface, BPs are slowly released into the bone matrix where they affect osteoclasts by reducing their differentiation, recruitment, and activity. In fact, it is believed that BPs are taken up by osteoclasts during bone resorption and, under their influence, osteoclasts 


\section{COPYRIGHT $^{\circledR} 2018$ EDIZIONI MINERVA MEDICA}

lose their ruffled border and their normal cytoskeleton structure. 4,6

Clodronate, that seems able to most closely mimic pyrophosphate, behaves as inorganic pyrophosphate analogue by being metabolically incorporated into non-hydrolysable analogues of ATP though the reversal of the actions of aminoacyl-tRNA synthetases. The resulting metabolites contain the P-C-P moiety in place of the $\beta, \gamma$-phosphate groups of ATP, thus resulting in non-hydrolysable nucleotides. ${ }^{7,8}$ It is likely that intracellular accumulation of these metabolites within osteoclasts inhibits their function and may cause osteoclast cell death, probably by interference with mitochondrial ATP translocases. ${ }^{9}, 10$ NNBPs, such as clodronate, therefore appear to act essentially as prodrugs, being converted to active drug metabolites following intracellular uptake by osteoclasts in-vivo.

Figure 1 summarizes the mechanism of action of clodronate. Once absorbed, the drug enters in macrophages by endocytosis process, and then is metabolized to $\mathrm{AppCCl}_{2} \mathrm{p}$ (a non-hydrolysable ATP analogue) by aminoacyl-tRNA synthetase. This metabolite shows immediate effects on mitochondrial membrane potential, and also causes cellular apoptosis. ${ }^{9}$ A biphasic effect on mitochondrial membrane potential has been observed. The direction of the initial change (increase in membrane potential) suggests that $\mathrm{AppCCl}_{2} \mathrm{p}$ somehow inhibits his dissipation. The electrogenic ADP/ATP translocase (ANT) is one consumer of the membrane potential. Inhibition of the ANT would therefore account for the initial rise in

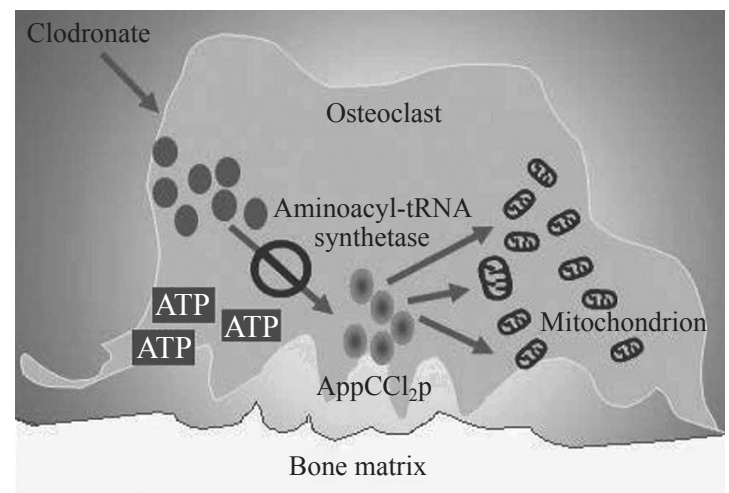

Figure 1.-Mechanism of action of clodronate (from Saviola et al., ${ }^{3}$ courtesy of Biolife Sas). mitochondrial membrane potential. ${ }^{10}$ The subsequent decrease is probably due to some secondary adverse effects on the mitochondrial energy state. $\mathrm{AppCCl}_{2} \mathrm{p}$ is a competitive inhibitor with respect to ATP, and this metabolite could therefore interfere with several aspects of mitochondrial metabolism connected to respiratory chain, such as pyrophosphate translocation into the inner membrane. Early mitochondrial events in cellular apoptosis include dissipation of its membrane potential, increased levels of $\mathrm{Ca}^{2+}$, NADPH oxidation, burst of reactive oxygen species, increased opening of the mitochondrial permeability transition (PT) pore, and release of cytochrome $\mathrm{c}$ and other pro apoptotic factors into the extra-mitochondrial space. ANT form the PT pore when associated with cyclophilin-D in the mitochondrial matrix and the non-selective voltage-dependent anion channel in the mitochondrial outer membrane. Cyclosporin A and some ANT inhibitors inhibit PT pore formation, while others ANT inhibitors promote it. Because the ANT is clearly involved in controlling the PT pore and hence in regulation of apoptosis, it could be a target of $\mathrm{AppCCl}_{2} \mathrm{p}$ type metabolites of NNBPs such as clodronate. Data indicate that the ANT is indeed inhibited by $\mathrm{AppCCl}_{2}$ p. By inhibiting ANT, this metabolite could also cause opening of the PT pore and hence cause apoptosis. The effect of ANT inhibition on PT pore formation depends on whether the ligands bind to the $\mathrm{m}$-state or the c-state. Ligands binding the m-state inhibit the formation of the PT pore and ligands binding to the c-state induce the formation of the PT pore. If $\mathrm{AppCCl}_{2} \mathrm{p}$ acts as an enhancer of PT pore formation, it would be expected to do this by acting as a ligand binding to the c-state of the ANT. Thus, the pro-apoptotic effects of $\mathrm{AppCCl}_{2} \mathrm{p}$ may be similar to that of the other ANT inhibitors. The concentration of Ap$\mathrm{pCCl}_{2} \mathrm{p}$ needed to affect the ANT $\left(\mathrm{IC}_{50}=50 \mathrm{uM}\right)$ and disrupt mitochondrial membrane potential is reasonably low. 10,11 As previously described, clodronate has been shown to be metabolized into the non-hydrolysable ATP analogue AppC$\mathrm{Cl}_{2}$ p by aminoacyl-tRNA synthetase. Because of the similarities between ATP and this analogue, it has been found that this metabolite could act via the ATP-purinergic receptor pathway leading to an anabolic response. Once the drug has been 


\section{COPYRIGHT $^{\circledR} 2018$ EDIZIONI MINERVA MEDICA}

absorbed from chondrocytes (by pinocytosis) and metabolized, is then released by pannexin- 1 hemi-channel in the extracellular space. Next step is its bond to purinergic $\mathrm{P} 2$ receptors, such as $\mathrm{P}_{2} \mathrm{X}$ and $\mathrm{P}_{2} \mathrm{Y}$ receptors, on articular chondrocyte's surface. Chondrocytes utilize the purinergic receptor pathway as a part of the mechano-transduction cascade in which ATP is released through connexin-43, pannexin-1 hemi-channels and/or ANK into the extracellular space, where it can bind and signal through a variety of purinergic $\mathrm{P} 2$ receptors. $\mathrm{P}_{2} \mathrm{Y}$ receptors are $\mathrm{G}$ protein coupled receptors which utilize $\mathrm{IP}_{3}-\mathrm{CA}^{2+}$ second messenger system, leading to the stimulation of extracellular matrix (ECM) gene expression and protein synthesis, such as collagen and proteoglycans, while P2X receptors may have both catalytic functions and regulate hemi-channel activity, through their interaction with pannexins. Stimulation by clodronate resulted in a 3 -fold increase in $\mathrm{Ca}^{2+}$ signalling and anabolic effects on cartilaginous ECM biosynthesis. As approximately $70 \%$ of clodronate-induced $\mathrm{Ca}^{2+}$ signalling was abolished by inhibiting $\mathrm{P}_{2} \mathrm{X}$ receptors, this suggests that the

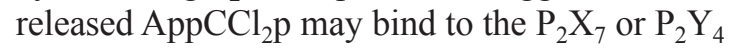
receptor leading to additional release through its known association with pannexin-1. Extracellular $\mathrm{AppCCl}_{2} \mathrm{p}$ then binds to $\mathrm{P}_{2} \mathrm{Y}$ receptors (most likely $\mathrm{P}_{2} \mathrm{Y}_{2}$ ) leading to the release of intracellular calcium from intracellular stores trough the $\mathrm{IP}_{3}$ second messenger system. ${ }^{12,13}$

Moreover, the drug shows anti-inflammatory and analgesic efficacy, which may be related to its pro-apoptotic action on macrophages, stopping their nitric oxide (NO) and pro-inflammatory cytokines (such as TNF $\alpha$ and IL $1 \beta$ ) release. ${ }^{9,}, 14$ All these molecules, secreted from damaged articular chondrocytes during osteoarthritis early stages, also promote cartilage erosion and subchondral bone alterations, and inhibit precursor maturation into chondrocytes. Clodronate could therefore influence the natural history of this disease and stimulate chondrocytic differentiation by regulating inflammatory pathways. ${ }^{10,13,15}$

\section{Clodronate in primary osteoporosis}

BPs are the most well established class of drugs in the treatment of post-menopausal osteoporosis. BPs are characterized by a high affinity for bone but not for other tissues, their main cellular targets being mesenchymal cells, osteocytes, osteoblasts, and osteoclast precursors. These agents have the ability to increase bone mineral density (BMD), reduce bone turnover markers, and ultimately decrease the risk of osteoporotic fractures. ${ }^{16,17}$

In-vitro studies have demonstrated the ability of clodronate in inhibiting reversibly the growth and glycolysis of fibroblasts and osteoclasts. Inhibition of osteoclastic activity reduces the firing rate of new bone remodeling units, with an altered balance between bone formation and resorption in favor of the latter, accounting for the effects of clodronate in the prevention and treatment of postmenopausal osteoporosis. ${ }^{17}$

The efficacy of clodronate in the management of osteoporosis in postmenopausal women has been documented in several studies carried across more than two decades, which have shown the effects of clodronate administered using different routes of administration and dose schedules, not only in increasing BMD, but also in reducing fragility-related fractures. Table I 18-34 summarizes the results of studies with clodronate in the treatment of post-menopausal osteoporosis.

Effects of clodronate on BMD in patients with osteoporosis

In the first study data carried out in $1993,{ }^{18}$ postmenopausal women with OP were treated with oral clodronate every two months at a dose of 400 $\mathrm{mg}$ /day, taken for 12 months. BMD increased significantly at the lumbar spine compared with untreated patients, in which BMD decreased by about $2 \%$, and these positive effects were already significant after the first 6 months of therapy. The same study group compared the continuous and the cyclical (30-day on followed by 60 -day off) regimen of oral clodronate $400 \mathrm{mg}$ /day in postmenopausal $\mathrm{OP},{ }^{20}$ and found that clodronate induced a gain in bone mass, especially in the spine. However, the continuous regimen did not result in any further benefit in lumbar bone density over the cyclical one, probably because of a greater suppression of bone turnover.

In a double-blind, placebo-controlled trial, ${ }^{27}$ 593 women with postmenopausal $(\mathrm{N} .=483)$ or secondary $(\mathrm{N} .=110)$ osteoporosis were evaluated for three years. The oral administration of clo- 


\section{COPYRIGHT $^{\circledR} 2018$ EDIZIONI MINERVA MEDICA}

TABLE I.-Results of studies with clodronate in the treatment of primary osteoporosis.

\begin{tabular}{|c|c|c|}
\hline Reference & $\begin{array}{l}\text { Diagnosis } \\
\text { N. of patients }\end{array}$ & Treatment groups, dose regimen and duration \\
\hline Giannini et al., 199318 & $\begin{array}{c}\text { PM OP } \\
60\end{array}$ & $\begin{array}{l}\text { A) Oral clodronate } 400 \mathrm{mg} \text { daily for } 30 \text { days, followed by } 60 \text { days of no treatment } \\
\text { ( } 4 \text { cycle repeated four times) } \\
\text { B) Oral calcitriol } 2 \mu \mathrm{g} \text { for } 5 \text { days and oral clodronate } 400 \mathrm{mg} \text { daily for additional } \\
25 \text { days, followed by } 60 \text { days of no treatment ( } 4 \text { cycles) } \\
\text { C) No treatment }\end{array}$ \\
\hline Filipponi et al., $1995^{19}$ & $\begin{array}{c}\text { PM OP } \\
124\end{array}$ & $\begin{array}{l}\text { A) i.v. clodronate } 200 \mathrm{mg} \text { every month for } 2 \text { years } \\
\text { B) Transcutaneous } 17-\beta \text {-estradiol } 50 \mu \mathrm{g} \text { daily for } 2 \text { years } \\
\text { C) Untreated controls }\end{array}$ \\
\hline Giannini et al., $1996^{20}$ & $\begin{array}{l}\text { PM OP } \\
60\end{array}$ & $\begin{array}{l}\text { A) Oral clodronate } 400 \mathrm{mg} \text { daily for } 12 \text { months (plus calcium) } \\
\text { B) Oral clodronate } 400 \mathrm{mg} \text { daily for } 30 \text { days, followed by a } 60 \text {-day period with } \\
\text { calcium alone (up to } 12 \text { months) } \\
\text { C) Calcium } 1000 \mathrm{mg} \text { daily for } 12 \text { months }\end{array}$ \\
\hline Filipponi et al., $1996^{21}$ & $\begin{array}{l}\text { PM OP } \\
\quad 235 \\
(183 \text { acted as } \\
\text { retrospective } \\
\text { controls) }\end{array}$ & i.v. clodronate $200 \mathrm{mg}$ every 3 weeks for up to 6 years \\
\hline Heikkinen et al., 199722 & $\begin{array}{c}\text { PM women } \\
107\end{array}$ & $\begin{array}{l}\text { A) i.v. clodronate } 150 \mathrm{mg} \text { once weekly for } 3 \text { weeks } \\
\text { B) i.v. clodronate } 300 \mathrm{mg} \text { once weekly for } 3 \text { weeks } \\
\text { C) i.v. clodronate } 600 \mathrm{mg} \text { once weekly for } 3 \text { weeks } \\
\text { D) i.v. etidronate } 300 \mathrm{mg} \text { once weekly for } 3 \text { weeks } \\
\text { E) i.v. placebo once weekly for } 3 \text { weeks }\end{array}$ \\
\hline Rossini et al., 199923 & $\begin{array}{c}\text { PM OP } \\
90\end{array}$ & $\begin{array}{l}\text { A) i.m. clodronate } 100 \mathrm{mg} \text { every two weeks for } 3 \text { years } \\
\text { B) i.m. clodronate } 100 \mathrm{mg} \text { every week for } 3 \text { years } \\
\text { C) Untreated controls }\end{array}$ \\
\hline
\end{tabular}

Filipponi et al., $2000^{24}$

PM OP A) Oral clodronate $400 \mathrm{mg}$ for 2 years

120 B) i.m. clodronate $100 \mathrm{mg}$ every 10 days for 2 years

C) i.v. clodronate $1800 \mathrm{mg}$ in one single infusion every 6 months for 2 years

D) i.v. clodronate $300 \mathrm{mg}$ in 6 consecutive days every 6 months for 2 years

E) Untreated controls

Gnudi et al., $2001^{25}$

PM OP A) i.m. clodronate $100 \mathrm{mg}$ every 10 days for 2 years (plus calcium)

36 B) Calcium only every 10 days for 2 years

Celi et al., 200326
PM OP 84

$\mathrm{PM}$ or secondary OP 593
A) i.v. clodronate $300 \mathrm{mg}$ every 2 weeks for 2 years (plus calcium/vitamin D)

B) i.v. clodronate $100 \mathrm{mg}$ weekly for 2 years (plus calcium/vitamin D)

C) Calcium/vitamin D

McCloskey et al., 200427

Muscoso et al., $2004^{28}$

Elderly PM OP A) i.m. clodronate $100 \mathrm{mg}$ weekly for 2 years

2000
A) Oral clodronate $800 \mathrm{mg}$ daily for 3 years

B) Oral placebo daily for 3 years 


Results of efficacy

Lumbar BMD significantly increased at both 6 and 12 months of therapy in group A and B $(+3.88 \pm 0.65 \%$ and $+3.21 \pm 0.89 \%$, respectively, at month 12 ), compared to a significant decline in untreated patients.

At 2 years, the mean spine BMD increased from baseline in group A $(0.67 \pm 0.84 \%)$ compared to no substantial changes in group B $(-0.14 \pm 0.93 \%)$ and decreased of more than $7 \%$ in untreated controls. A satisfactory change in BMD $(<1 \%)$ was obtained in $32 \%$ of the controls, in $79 \%$ of the estradiol group and in $90 \%$ of the clodronate-treated patients.

Patients in group $\mathrm{C}$ had a significant decline in spinal and femoral BMD, both at 6 and 12 months. Both clodronate-treated groups had increased levels of lumbar BMD compared with controls, both after 6 and 12 months. At the end of the study, patients in group B had higher spinal BMD compared with those of group A $(3.32 \pm 0.71 \% v s .0 .43 \pm 0.89 \%, \mathrm{P}<0.02)$. At 6 months, femoral BMD was significantly higher in subjects treated with both cyclical and continuous clodronate compared to controls $(\mathrm{P}<0.01)$.

BMD increased significantly and the upward trend persisted for all 6 years of therapy $(5.69 \pm 0.18 \%) v s$. controls: $-1.47 \pm 0.81 \%$, $\mathrm{P}<0.0001)$. The increase in BMD was greater in the 145 patients without vertebral fractures before starting clodronate. From year 3 onward clodronate reduced the incidence of new vertebral fractures. In patients and controls monitored for 3 and 4 years, respectively, the number of patients developing new vertebral fractures fell significantly in the clodronate group $(\mathrm{P}=0.067$ and $\mathrm{P}<0.003$, respectively).

During the first year, $300 \mathrm{mg}$ of clodronate retarded bone loss significantly in the lumbar spine and femoral neck, where significant protection still persisted after 24 months. Other doses of clodronate (150 and $600 \mathrm{mg}$ ) were not bone protective. Etidronate $(300 \mathrm{mg}$ ) retarded bone loss significantly in the lumbar spine up to 24 months, relative to placebo.

In group B, spinal BMD rose by $3.8 \pm 7.3 \%$ at the $6^{\text {th }}$ month and, at the completion of 3 years of observation, the mean gain was $4.5 \pm-6.3 \%$. In group A, the increase in BMD was somewhat lower and slower, becoming significant only at month 24 $(2.9 \pm 4.6 \%)$. The femoral neck BMD did not change significantly during the 3 years of the study in none of the clodronate groups. In control group, a progressive, slow decline in spine and femoral BMD, which was statistically significant at the end of the second year of observation, was observed. In both treated groups, the hip BMD changes were significantly different from those in control group.

After 2 years, continuous clodronate regimens (group A and B) caused an increase in BMD both at lumbar spine $(2.69 \%$ and $3.07 \%$, respectively) and proximal femur $(2.09 \%$ and 2.12 , respectively). Intermittent clodronate administration (group C and D) was associated with a small increase or a stabilization in BMD $(0.53 \%$ and $1.22 \%$ at lumbar spine and $0.30 \%$ and $0.77 \%$ at femoral neck, respectively). From the $12^{\text {th }}$ month, changes in spine and femoral neck BMD after continuous regimens were statistically higher compared to intermittent regimens.

In the control group a progressive but not statistically significant decrease in BMD was observed in the spine and femoral neck over the 2-year follow-up. In contrast, patients treated with clodronate had a statistically significant increase in BMD in the spine at the first yearly check-up $(2.63 \%)$ and a further but not statistically significant increase during the second year of treatment $(0.59 \%)$. The increase in BMD at the femoral neck was not statistically significant during the first and second years of treatment, being $1.21 \%$ and $0.37 \%$ respectively.

In groups $\mathrm{A}$ and $\mathrm{B}$, a significantly greater $(\mathrm{P}<0.05)$ increase in the lumbar $\mathrm{BMD}$ with respect to group $\mathrm{C}$ was observed after 6 months of treatment. After 12 months of therapy, in group A the lumbar BMD $(1.8 \% \pm 0.5 \%)$ was significantly higher $(\mathrm{P}<0.05)$ than that in group B $(0.9 \pm 0.3 \%)$. At the end of the study, in groups $\mathrm{A}(1.2 \pm 0.5 \%)$ and $\mathrm{B}(1.1 \pm-0.4 \%)$ the percentage increase in the femoral neck BMD was significantly greater $(\mathrm{P}<0.05)$ than in group $\mathrm{C}(0.6 \pm 0.5 \%)$. After 24 months of therapy, there was no difference in the femoral neck BMD between groups A and B.

Treatment with clodronate was associated with a significant increase from baseline in mean spine BMD over 3 years $(4.35 \pm 6.34 \% v s .0 .64 \pm 6.02 \%$ in the placebo group, $\mathrm{P}<0.0001)$. At the hip, clodronate maintained total BMD, whereas a significant decrease was observed in the placebo group (percent change from baseline $0.70 \pm 5.67 \% v s .-3.03 \pm 6.32 \%$ in the placebo group, $\mathrm{P}<0.0001)$. Incident vertebral fractures at 3 years were observed in 63 women $(23.3 \%)$ in the placebo group and 33 patients $(12.7 \%$ ) receiving clodronate (relative risk, $0.54 ; 95 \% \mathrm{CI}, 0.37-0.80 ; \mathrm{P}=0.001$ ). Clodronate significantly reduced the risk of vertebral fracture in both post-menopausal and secondary OP subgroups, and in women with or without prior vertebral fracture at baseline.

A significant increase in BMD after a 24-month treatment period was observed in the BPs groups. A total of 18 osteoporosisrelated fractures were observed during the entire study period; 10 out of 18 fractures occurred in the alendronate group, whereas the remaining 8 fractures were observed in the clodronate group.

(To be continued) 


\section{COPYRIGHT $^{\circledR} 2018$ EDIZIONI MINERVA MEDICA}

TABLE I.-Results of studies with clodronate in the treatment of primary osteoporosis (continues).

\begin{tabular}{|c|c|c|}
\hline Reference & $\begin{array}{c}\text { Diagnosis } \\
\text { N. of patients }\end{array}$ & Treatment groups, dose regimen and duration \\
\hline Dominguez et al., $2005^{29}$ & $\begin{array}{l}\text { PM OP } \\
250\end{array}$ & $\begin{array}{l}\text { A) i.m. clodronate } 100 \mathrm{mg} \text { weekly for } 12 \text { months (plus calcium/vitamin D) } \\
\text { B) i.m. clodronate } 100 \mathrm{mg} \text { every two weeks for } 12 \text { months (plus calcium/vitamin D) } \\
\text { C) Calcium/vitamin D only }\end{array}$ \\
\hline
\end{tabular}

McCloskey et al., 200730 Elderly women A) Oral clodronate $800 \mathrm{mg}$ daily for 3 years (plus calcium) $5579 \quad$ B) Oral placebo daily for 3 years (plus calcium)

Tanakol et al., $200731 \quad$ PM OP

Muratore et al., $2010^{32}$

Frediani, $2011^{33}$

岸

范兽

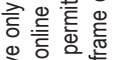

离 등 믇응

Frediani et al., $2013^{34}$
PM OP

60
89

A) Oral clodronate $800 \mathrm{mg}$ daily for 3 years (plus calcium/vitamin D)

B) Calcium/vitamin D only

\section{PM OP}

A) i.m. clodronate $100 \mathrm{mg}$ weekly for 12 months

60

B) i.m. clodronate $200 \mathrm{mg}$ every two weeks for 12 months

PM OP

A) i.m. clodronate $100 \mathrm{mg}$ weekly for 2 years

60

B) i.m. clodronate $200 \mathrm{mg}$ every two weeks for 2 years
A) i.m. clodronate $100 \mathrm{mg}$ weekly for 2 years

B) i.m. clodronate $100 \mathrm{mg}$ twice weekly for 2 years

PM: postmenopausal; OP: osteoporosis; BMD: bone mineral density; i.v.: intravenous; i.m.: intramuscular; HR: hazard ratio.

dronate at a dose of $800 \mathrm{mg} /$ day was associated with a significant increase in BMD at the lumbar spine and total hip compared with placebo. At the same oral dosage of $800 \mathrm{mg} /$ day, clodronate was shown to reduce the loss of femoral bone mass in a large institutionalized elderly population. ${ }^{30}$

Further confirmation of the effectiveness of oral clodronate $800 \mathrm{mg}$ /day on BMD has been reported in a small randomised clinical trial lasting three years conducted in postmenopausal osteoporosis women. ${ }^{31}$

Several studies have evaluated the effects of parenteral administration of clodronate. In a comparative study vs. transcutaneous 17-betaestradiol (50 $\mu \mathrm{g}$ daily) and untreated controls, ${ }^{19}$ treatment with i.v. clodronate $200 \mathrm{mg} / \mathrm{month}$ for 2 years was associated with an increase in spine BMD compared to no changes in the estradiol group and a decrease in controls.
Another open-label study 21 evaluated the changes in BMD in 235 postmenopausal women with osteoporosis treated every 3 weeks with $200 \mathrm{mg}$ of clodronate i.v. and followed annually for six years, compared with a control group of 183 women observed retrospectively. The results showed a significant increase in BMD in the first year of treatment, and the effect was maintained over six years. Based on these results, a subsequent study conducted by the same group ${ }^{24}$ evaluated the administration of clodronate continuously (oral or i.m.) or intermittently (i.v.). Continuous clodronate regimens determined an increase in both lumbar spine and proximal femur BMD, whereas intermittent clodronate administration was associated with a small increase or a stabilization in bone mass.

When given i.v. at a dose of $300 \mathrm{mg}$ infused 3 times in one-week intervals, clodronate was 


\section{COPYRIGHT $^{\odot} 2018$ EDIZIONI MINERVA MEDICA}

Results of efficacy

A significant increase in mean BMD was observed at the lumbar spine in patients receiving clodronate (4.21\% in group A and $2.98 \%$ in group B), whereas no significant changes were reported in patients receiving only calcium and vitamin $\mathrm{D}(-0.50 \%)$. The difference between groups $\mathrm{A}$ and $\mathrm{B}$ was statistically significant at both the lumbar spine $(\mathrm{P}=0.02)$ and the femoral neck $(\mathrm{P}=0.05)$. Increases at all femoral sites were also observed in the clodronate groups.

A new hip fracture during the 3-year treatment phase occurred in $56(2.0 \%)$ women in the clodronate group and in $58(2.1 \%)$ in the placebo group (hazard ratio [HR], 1.02; 95\% CI, 0.71-1.47). Clodronate did, however, decrease the incidence of any clinical fracture by $20 \%$ (264 women [9.5\%] versus 337 [12.1\%] in the placebo group; HR, 0.80; 95\% CI, 0.68-0.94). The incidence of OP-associated non-hip fractures was also significantly decreased by $29 \%$ in the clodronate group (5.2\% versus $7.4 \%$; HR, 0.71 ; $95 \%$ CI, 0.57-0.87). In women with hip measurements, the mean decrease in BMD was $61 \%$ lower in the clodronate group compared to placebo.

Treatment with clodronate significantly increased mean femoral neck BMD by $3.2 \pm 2.9 \%$, trochanter BMD by $2.2 \pm 2.9 \%$ and lumbar spine BMD by $3.1 \pm 3 \%$. In the control group, femoral neck, trochanter and lumbar spine BMD decreased by $-6 \pm 2.7 \%$, $-7.3 \pm 2.5 \%$ and $-5.4 \pm 2 \%$, respectively $(\mathrm{P}<0.01, \mathrm{P}<0.05$ and $\mathrm{P}<0.05$ between groups, respectively).

A significant increase of lumbar and femoral BMD at 12 months $v$ s. baseline was reported in both groups. In group A lumbar BMD increased by $3.5 \%$ and femoral BMD by $2.1 \%$; in group B, lumbar and femoral BMD rose by $3.4 \%$ and $2.2 \%$, respectively. No difference was observed between groups. Bone resorption markers significantly decreased from baseline.

Significant increases in mean BMD of the lumbar spine versus baseline were observed in both groups at 1 and 2 years (group A - year 1: $2.8 \pm 1.7 \%, \mathrm{P}<0.05$; year $2: 3.5 \pm 2.2 \%, \mathrm{P}<0.01$; group B - year 1: $2.7 \pm 2.1 \%, \mathrm{P}<0.05$; year $2: 3.9 \pm 2.2 \%, \mathrm{P}<0.01)$. Mean BMD at the femoral neck also significantly increased versus baseline in group A at both time-points (year 1: 2.3 $\pm 1.9 \%$, $\mathrm{P}<0.05$; year $2: 2.5 \pm 1.9 \%, \mathrm{P}<0.05$ ), while the increase in group B was significant only at 2 years (year $1: 1.9 \pm 2.2 \%$; year 2 : $2.8 \pm 1.8 \% ; \mathrm{P}<0.05)$. Significant increases in total femur BMD were observed only in group A at 2 years $(2.4 \pm 1.9 \%, \mathrm{P}<0.05)$. No differences between groups were reported.

Significant increases $v s$. baseline in BMD were observed in both groups at 1 and 2 years, with significantly higher increases in group B compared to group A. The increase in BMD at the lumbar spine in group B was $4.0 \pm 2.1 \%$ and $5.9 \pm 2.0$ at 1 and 2 years, respectively, compared with $2.8 \pm 1.7$ and $3.5 \pm 2.2 \%$, respectively, in group A. Similarly, group B had a greater increase of BMD at femoral neck $(3.5 \pm 1.7 \%$ and $+5.4 \pm 1.8 \%$ at 1 and 2 years, respectively), compared with a change of $2.3 \pm 1.9 \%$ and $2.5 \pm 1.9 \%$, respectively, in group A. The BMD increase measured at the total femur was also significantly higher for Group B (3.4 $\pm 1.9 \%$ and $4.9 \pm 2.1 \%$ at years 1 and 2 , respectively) compared to group A ( $1.6 \pm 0.9 \%$ and $2.4 \pm 1.9 \%$ at years 1 and 2 , respectively).

shown to counteract postmenopausal bone loss for at least one year in the lumbar spine and up to two years in the femoral neck. ${ }^{22}$

In a comparative study 26 of two different regimens of i.v. clodronate ( $300 \mathrm{mg}$ every two weeks and $100 \mathrm{mg} / \mathrm{week}$ ) given in postmenopausal osteoporosis women intolerant to amino-BPs, both dose schedules were associated with significant increases in BMD at lumbar spine and femoral neck up to 24 months, however with more marked effects at the lumbar spine with the 300 mg dose every two weeks at 12 months.

Positive results have also emerged from the use of clodronate i.m. in the treatment of postmenopausal osteoporosis. In 1999 Rossini et al. ${ }^{23}$ showed that, after two years of treatment with clodronate i.m. at a dose of $100 \mathrm{mg}$ every two weeks or every week (with oral calcium supplementation), the treated group had significant increases in lumbar and femoral BMD compared with the control group (treated only with calcium supplementation). Statistically significant increases in BMD at the lumbar spine were also observed when i.m. clodronate $100 \mathrm{mg}$ was administered every 10 days for 2 years. ${ }^{25}$

In a study in 250 postmenopausal women, Dominguez et al. compared weekly i.m. administration of clodronate $100 \mathrm{mg}$ with the same dose given every two weeks, and found that both regimens determined a statistically significant improvement in BMD compared with the control group treated only with calcium and vitamin D supplementation. Nevertheless, the largest increases in BMD at the lumbar spine and femoral neck were reported in the group of patients treated with clodronate $100 \mathrm{mg}$ per week. ${ }^{29}$

More recent trials have been conducted in women with postmenopausal osteoporosis to 


\section{COPYRIGHT $^{\circledR} 2018$ EDIZIONI MINERVA MEDICA}

assess the most appropriate schedule regimen in the administration of i.m. clodronate and hence to evaluate whether less frequent dosing regimens may promote an improved adherence to treatment while maintaining the same efficacy. Similarity of effects on BMD increase at 12 months between the i.m. clodronate $200 \mathrm{mg}$ twice-a-month and the $100 \mathrm{mg} /$ week regimens (i.e. at the same overall dose) has been shown in the first of these studies. ${ }^{32}$ Another study 33 that tested the same dosing regimens, in which the clodronate $200 \mathrm{mg}$ every 2 weeks dose was given in two $100 \mathrm{mg}$ injections on two consecutive days, confirmed the similarity of effects on BMD at lumbar spine and femoral neck between the new proposed dose schedule and the $100 \mathrm{mg} /$ week regimen. In another study in postmenopausal osteoporosis, the same author reported a superior increase of lumbar and femoral BMD of i.m. clodronate $200 \mathrm{mg} /$ week (100 mg twice weekly) over the $100 \mathrm{mg}$ once/week regimen, 34 thus suggesting a dose-dependent densitometric effect of i.m. clodronate.

\section{Effects on fracture risk in patients with osteoporosis}

The effects of clodronate in reducing the incidence of vertebral fractures were first observed in the study published in 1996,21 in which longterm treatment with i.v. clodronate $200 \mathrm{mg}$ every 3 weeks was associated with a significant reduction in incidence of vertebral fractures compared to controls, which was more evident in the subgroup that did not present fractures at baseline.

The efficacy of oral clodronate in reducing the risk of skeletal fractures was demonstrated in the 3-years double-blind trial of McCloskey et al., ${ }^{27}$ in which the incidence of vertebral fractures was reduced by $46 \%$ in the clodronate group compared to placebo. This reduction reached statistical significance after one year of therapy.

In the randomized controlled trial involving 5592 institutionalised women aged $\geq 75$ years, ${ }^{30}$ 56 patients $(2.0 \%)$ in the clodronate group and $58(2.1 \%)$ in the placebo group had a new hip fracture during the 3-year treatment phase. However, clodronate reduced the incidence of any clinical fracture by $20 \%$ relative to placebo $(9.5 \%$ vs. $12.1 \%)$, as well as the incidence of os- teoporosis-associated non-hip fractures was also significantly decreased by $29 \%$ in the clodronate group compared to placebo (5.2\% vs. $7.4 \%)$.

Another study in elderly patients has demonstrated the anti-fracture efficacy of i.m. clodronate compared with other BPs, including alendronic acid.28 Notably, in this study improvements in BMD were poor predictive of the risk of new fractures, which resulted to be age-related.

The results of a recent meta-analysis have demonstrated that clodronate is effective in reducing the risk of vertebral, non-vertebral, and overall fractures in patients with skeletal fragility due to intense osteoclast activity, such as cancer diseases, multiple myeloma, post-menopausal and secondary OP. 35

\section{Clodronate in secondary osteoporosis}

The heterogeneous group of secondary osteoporosis includes all cases of osteoporosis in which other causes to menopause and aging are identified, and may be the result of one or more of the following factors: systemic diseases, endocrine diseases, gastro-intestinal diseases, malignant neoplasms and other hematologic conditions, chronic use of glucocorticoids and other drugs, lifestyle conditions and habits.

\section{Effects of clodronate in glucocorticoid-induced os- teoporosis}

Glucocorticosteroid-induced osteoporosis (GIOP) is the most common form of secondary osteoporosis and the first iatrogenic cause of osteoporosis. Bone loss and increased rate of fractures occur early after the initiation of corticosteroid therapy, and are related to dosage and treatment duration. Response to treatment of GIOP is not different from that of postmenopausal osteoporosis and therefore antiresorptive therapy including BPs remains the first therapeutic option. ${ }^{36}$

Different trials have shown the effects of clodronate, in any of the available formulations (oral, i.m. and i.v.), in preventing bone loss or increasing bone mass in patients with GIOP (Table II). ${ }^{37-51}$ The first study 40 was conducted in 74 adult asthmatic patients with a long history of continuous oral and inhaled corticosteroid administration, who were assigned to treat- 


\section{COPYRIGHT $^{\circledR} 2018$ EDIZIONI MINERVA MEDICA}

ment with three different daily doses of clodronate $(800,1600$ or $2400 \mathrm{mg})$ or placebo, for 12 months. Significant increases from baseline to 12 month in BMD at lumbar spine were observed with clodronate 1600 and $2400 \mathrm{mg}$, with a significant dose-response effect, and with clodronate $2400 \mathrm{mg}$ at the femoral neck and trochanter region. The i.m. formulation of clodronate in the treatment of GIOP was tested in another trial in 60 asthmatic patients, ${ }^{41}$ who were treated with clodronate $100 \mathrm{mg}$ every two weeks for one year. At the end of treatment, clodronate was effective in increasing BMD compared with baseline and compared with untreated controls, irrespective of the underlying inhaled corticosteroid therapy. In another trial ${ }^{47}$ conducted in 67 patients with inflammatory bowel disease (IBD) starting a steroid therapy, treatment with i.v. clodronate 300 mg once monthly for 3 months (900 mg in total) was associated with a stabilization of BMD at lumbar spine and femoral neck at one year, compared to significant decreases of BMD at both skeletal sites in patients receiving placebo.

\section{Effects of clodronate in other forms of secondary osteoporosis}

In addition to the above-reported studies in GIOP, clodronate was also effective in the treatment of patients with subclinical Cushing's Syndrome (SCS) and osteoporosis or osteopenia, ${ }^{50}$ who were treated with i.m. $100 \mathrm{mg} /$ week plus calcium and vitamin D for 12 months or only with supplemental therapy. Patients treated with clodronate had increased lumbar BMD, preserved bone mass at the femoral neck, stabilized vertebral fracture index, and decreased subjective back pain, compared to increased bone loss and unchanged pain in the untreated control group.

BPs may be used in rheumatoid arthritis or in other inflammatory autoimmune joint diseases due to their effects on osteoclasts, which play a key role in the bone loss process that accompanies the joint damage in arthritis. 52 The anti-inflammatory effects of clodronate may add further beneficial effects in the treatment of inflammatory joint diseases. In a study in 163 patients with rheumatoid or psoriatic arthritis starting steroid therapy, 45 who were randomised to receive i.m clodronate $100 \mathrm{mg} /$ week plus calcium and vitamin D or calci- um/vitamin D supplementation alone, for 4 years. BMD did not change significantly in the clodronate plus calcium and vitamin $\mathrm{D}$ group, whereas it declined significantly in the control group. The difference between groups at 48 months was significant for BMD at lumbar spine, femoral neck, trochanter, total femur and total body. The relative risk of vertebral fractures and multiple vertebral fractures in the clodronate group compared to the calcium plus vitamin D group was 0.63 and 0.25 , respectively. The overall risk reduction was evident in both premenopausal (relative risk 0.56 ) and postmenopausal women (0.65). This is the only study demonstrating that intermittent i.m. administration of clodronate once weekly was effective in preventing vertebral fractures in GIOP.

Secondary osteoporosis can develop in patients with significant gastrointestinal failure and malabsorption, especially in those requiring parenteral nutrition. Although the exact cause of bone loss in patients undergoing parenteral nutrition is not known, it is believed that it has a multifactorial origin, with factors including underlying disease, effect of medications used to treat this disease (e.g. corticosteroids), and various components of the parenteral nutrition solution. ${ }^{53}$ In a placebo-controlled trial ${ }^{44}$ in 20 patients receiving home parenteral nutrition and low BMD, in which i.v. clodronate $1500 \mathrm{mg}$ was given every three months for one year, mean BMD at lumbar spine increased from baseline to end of treatment in the clodronate group and decreased in the placebo group, however not significantly between groups. BMD at the other secondary skeletal sites increased in the clodronate group. Treatment with clodronate was also associated with significant decreases in biochemical markers of bone resorption. Although conducted in a small number of patients, this study showed preliminary evidence that i.v. clodronate at the tested dosage may produce significant suppression of bone resorption in patients requiring parenteral therapy.

Clodronate i.m. or i.v has been successfully used also for the management of thalassemiaassociated osteoporosis, which represents one of the most complex and obstinate form of secondary osteoporosis. In general, patients with thalassemia-associated osteoporosis respond 


\section{COPYRIGHT $^{\circledR} 2018$ EDIZIONI MINERVA MEDICA}

TABLE II.-Results of studies with clodronate in the treatment of secondary osteoporosis.

\begin{tabular}{|c|c|c|}
\hline Reference & $\begin{array}{l}\text { Diagnosis } \\
\text { N. of patients }\end{array}$ & Treatment groups, dose regimen and duration \\
\hline Rizzoli et al., $1996^{37}$ & $\begin{array}{l}\text { Breast cancer } \\
\quad 67\end{array}$ & $\begin{array}{l}\text { A) Oral clodronate } 1600 \mathrm{mg} \text { daily for } 9 \text { months } \\
\text { B) Untreated controls }\end{array}$ \\
\hline Saarto et al., 199738 & $\begin{array}{l}\text { Breast cancer } \\
\quad 121\end{array}$ & $\begin{array}{l}\text { A) Oral clodronate } 1600 \mathrm{mg} \text { daily for } 3 \text { years (plus antiestrogens) } \\
\text { B) Untreated controls (antiestrogens only) }\end{array}$ \\
\hline Saarto et al., 199739 & $\begin{array}{l}\text { Breast cancer } \\
\quad 148\end{array}$ & $\begin{array}{l}\text { A) Oral clodronate } 1600 \mathrm{mg} \text { daily for } 2 \text { years (plus chemotherapy) } \\
\text { B) Untreated controls (chemotherapy only) }\end{array}$ \\
\hline Herrala et al., $1998^{40}$ & $\begin{array}{l}\text { GIOP in asthma } \\
74\end{array}$ & $\begin{array}{l}\text { A) Oral clodronate } 800 \mathrm{mg} \text { daily for } 12 \text { months } \\
\text { B) Oral clodronate } 1600 \mathrm{mg} \text { daily for } 12 \text { months } \\
\text { C) Oral clodronate } 2400 \mathrm{mg} \text { daily for } 12 \text { months } \\
\text { D) Placebo daily for } 12 \mathrm{months}\end{array}$ \\
\hline Muratore et al., $2000^{41}$ & $\begin{array}{l}\text { GIOP in asthma } \\
60\end{array}$ & $\begin{array}{l}\text { A) i.m. clodronate } 100 \mathrm{mg} \text { every two weeks for one year (plus } \\
\text { inhaled FP and oral calcium) } \\
\text { B) i.m. clodronate } 100 \mathrm{mg} \text { every two weeks for one year (plus } \\
\text { inhaled BDP and oral calcium) } \\
\text { C) Untreated controls (only inhaled FP and oral calcium) } \\
\text { D) Untreated controls (only inhaled BDP and oral calcium) }\end{array}$ \\
\hline $\begin{array}{l}\text { Saarto et al., } 2001^{42} \\
\text { (follow-up of }{ }^{38} \text { ) }\end{array}$ & $\begin{array}{l}\text { Breast cancer } \\
\quad 61\end{array}$ & $\begin{array}{l}\text { A) Oral clodronate } 1600 \mathrm{mg} \text { daily for } 3 \text { years (plus antiestrogens) } \\
\text { B) Untreated controls (antiestrogens only) }\end{array}$ \\
\hline $\begin{array}{l}\text { Vehmanen et al., } 2001^{43} \\
\text { (follow-up of }{ }^{39} \text { ) }\end{array}$ & $\begin{array}{l}\text { Breast cancer } \\
\quad 73\end{array}$ & $\begin{array}{l}\text { A) Oral clodronate } 1600 \mathrm{mg} \text { daily for } 3 \text { years (plus chemotherapy) } \\
\text { B) Untreated controls (chemotherapy only) }\end{array}$ \\
\hline Haderslev et al., $2002^{44}$ & $\begin{array}{c}\text { HPN } \\
20\end{array}$ & $\begin{array}{l}\text { A) i.v. clodronate } 1500 \mathrm{mg} \text { every three months for one year } \\
\text { B) i.v. placebo every three months for one year }\end{array}$ \\
\hline
\end{tabular}

Frediani et al., $2003^{45} \quad$ Prevention of GIOP in RA A) i.m. clodronate $100 \mathrm{mg}$ weekly for 48 months (plus calcium/ $163 \quad$ vitamin D)

B) Calcium/vitamin D only

Vehmanen et al., $2004^{46}$

Breast cancer 45

A) i.v. clodronate $1500 \mathrm{mg}$ once monthly for 9 months

Abitbol et al., $2005^{47}$

Prevention of GIOP in IBD A) i.v. clodronate $300 \mathrm{mg}$ once monthly for 3 months 67

B) i.v. placebo once monthly for 3 months

Rodrigues et al., 200748

ADT

A) i.v. clodronate $1500 \mathrm{mg}$ every month for 36 months

94

B) i.v. zoledronate $4 \mathrm{mg}$ every month for 36 months

을 을

든 흘 훌

Saarto et al., $2008^{49}$

(extended follow-up of ${ }^{38}$ )

Breast cancer 268

C) i.v. placebo every month for 36 months

Tauchmanova et al., 200950

SCS and OP/osteopenia 46

A) Oral clodronate $1600 \mathrm{mg}$ daily for 3 years (plus antiestrogens) 
BMD at lumbar spine, femoral neck and midfemoral shaft slightly increased in the clodronate group, compared to small decreases in controls. In 15 women without evident lumbar spine bone metastasis (7 clodronate-treated and 8 controls), mean lumbar spine BMD increased vs. baseline in the clodronate group by $+5.2 \pm 2.5 \% v s .-0.3 \pm 1.4 \%$, and $+8.1 \pm 4.7 \% v s$. $-0.9 \pm 1.7 \%$, after $10.3 \pm 0.4$ and $17.3 \pm 1.2$ months, respectively $(\mathrm{P}<0.01)$. The rate of bone complications (pathological fracture, hypercalcemic episode, scintigraphic or radiological evidence of metastasis development, chemo- or radiotherapy for bone disease progression) was 28.8 events/100 patient/year in the clodronate group vs. 39.0 in controls, and $31.5 v s$. 40.5 , after 9 and 15 months of follow-up, respectively.

At 2 years, clodronate with antiestrogens markedly increased BMD in the lumbar spine and femoral neck by $2.9 \%$ and $3.7 \%$ $(\mathrm{P}=0.001$ and $\mathrm{P}=0.006$ respectively). There were no significant changes in $\mathrm{BMD}$ in the patients given antiestrogens only.

Mean changes in BMD at lumbar spine and femoral neck were $-5.9 \%$ and $-2.0 \%$ without clodronate and $-2.2 \%$ and $+0.9 \%$ with clodronate at 2 years $(\mathrm{P}=0.0005$ and 0.017 , respectively). Patients who developed amenorrhea after chemotherapy had a rapid bone loss, which was significantly reduced by clodronate. In controls, bone loss was $9.5 \%$ at the lumbar spine and $4.6 \%$ at the femoral neck, while in the clodronate group, bone loss was $5.9 \%$ and $0.4 \%$, respectively, at 2 years.

Mean BMD at lumbar spine increased significantly from baseline to month 12 in the clodronate groups of $1600 \mathrm{and} 2400 \mathrm{mg} /$ day, i.e. $2.6 \%(\mathrm{P}<0.02)$ and $3.0 \%(\mathrm{P}<0.01)$, respectively, but not in the placebo and clodronate $800 \mathrm{mg} /$ day groups. The test for a linear dose trend (lumbar spine BMD percent change) at 12 months was significant $(\mathrm{P}<0.02)$. The mean BMD at femoral neck increased significantly in the $2400 \mathrm{mg}$ /day group, i.e. $(4.3 \%, \mathrm{P}<0.0001)$, as well as in the trochanter region $(2.8 \%, \mathrm{P}<0.02)$. Mean BMD at lumbar level significantly increased from baseline to month 12 in the groups receiving clodronate and significantly decrease in groups not receiving clodronate. A statistically significant increase in mean BMD at month 12 was observed in groups $\mathrm{A}$ and $\mathrm{B}$ compared to groups $\mathrm{C}$ and $\mathrm{D}$, respectively.

Al 3 years, clodronate slightly increased BMD at lumbar spine $(+1.0 \%$ vs. $-1.7 \%$ in controls, $\mathrm{P}=0.01)$ and at femoral neck $(+2.4 \%$ vs. $-0.4 \%, \mathrm{P}=0.12)$. At 5 years of follow-up, 2 years after the end of therapy, clodronate $v s$. controls was $-1.0 \% v s$. $-3.2 \%(\mathrm{P}=0.06)$ at lumbar spine and $-0.1 \%$ vs. $-5.2 \%(\mathrm{P}=0.001)$ at femoral neck.

Clodronate significantly reduced the bone loss in the lumbar spine $(-3.0 \%)$ compared with controls $(-7.4 \%)$ at three years $(\mathrm{P}=0.003)$, but no significant difference was found in the femoral neck $(-1.7 \%$ vs. $-2.8 \%, \mathrm{P}=0.86)$. These differences were still seen at 5 years: $-5.8 \%$ vs. $-9.7 \%$ at lumbar spine $(\mathrm{P}=0.008)$ and $-3.5 \%$ vs. $-5.1 \%$ at femoral neck $(\mathrm{P}=0.91)$.

The mean BMD at lumbar spine increased by $0.8 \% \pm 2.0 \%$ in the clodronate group and decreased by $1.6 \% \pm 2.0 \%$ in the placebo group ( $\mathrm{P}=0.43$ between groups). At all secondary skeletal sites (hip, total body and distal forearm), there were small increases in the BMD in the clodronate group and decreases in the placebo group. Biochemical markers of bone resorption decreased significantly in the clodronate group $(\mathrm{P}<0.05)$.

BMD did not change significantly in the clodronate group and declined significantly in control group. The difference between groups at 48 months in mean changes from baseline was $8.8 \pm 1.4 \%$ at lumbar spine $(\mathrm{P}<0.01), 7.3 \pm 1.1 \%$ at femoral neck $(\mathrm{P}<0.01), 7.9 \pm 1.9 \%$ at the trochanter $(\mathrm{P}<0.01), 8.4 \% \pm 1.8 \%$ for total femur $(\mathrm{P}<0.01)$, and $6.9 \pm 1.1 \%$ for total body $(\mathrm{P}<0.01)$. The relative risk of vertebral fractures in the clodronate group $v s$. controls was 0.63 (CI: 0.35-0.98).

The mean bone loss in the lumbar spine at 6 months was $-0.5 \%$ in the clodronate group and $-1.4 \%$ in the control group $(\mathrm{P}=0.22)$ and, at 12 months, $-3.9 \%$ and $-3.6 \%$, respectively in the two groups $(\mathrm{P}=0.62)$.

At 1 year, there was no change in mean BMD in the clodronate group, neither at the spine $(-0.2 \%$, NS) nor at the femoral neck $(2.3 \%, \mathrm{NS})$. In contrast, there was a significant decrease in mean BMD at both lumbar spine $(-2.0 \%, \mathrm{P}=0.0018)$ and femoral neck $(-1.7 \%, \mathrm{P}=0.045)$ in the placebo group.

At the end of the 36-month study period, the untreated group had a mean BMD loss (T score) of $-1.82 \pm 0.94$, with 13 cases of osteopenia and 18 cases of osteoporosis. The clodronate group had 28 cases of osteopenia and 7 cases of osteoporosis at 36 months, with a mean BMD loss of $-0.72 \pm 0.34$. The zoledronate arm had 20 and 5 cases of osteopenia and osteoporosis at month 36 , respectively, with a mean bone loss of $-0.88 \pm 0.32$.

During the 10-year period, 14 patients developed spinal osteoporosis (3/41 in the clodronate group, and 11/48 in the control group), and 14/89 patients were diagnosed with hip osteoporosis (7/41 in the clodronate group, and 7/48 in the control group). The 10-year spinal, osteoporosis-free survival rate was $92.7 \%$ in the clodronate group and $77.0 \%$ in the control group $(\mathrm{P}=0.035)$. No difference was seen in the frequency of hip osteoporosis $(85.4 \%$ vs. $82.9 \% ; \mathrm{P}=0.92)$.

After 12 months of treatment, a significant increase in lumbar BMD occurred in the clodronate group $(\mathrm{P}=0.04)$, while bone turnover markers decreased by about one third $(\mathrm{P}<0.05)$. In the control group, bone turnover markers did not change and mean BMD slightly decreased ( $\mathrm{P}=\mathrm{NS})$. The differences between groups in bone turnover markers and in lumbar BMD were significant $(\mathrm{P}<0.05)$. No new vertebral fracture occurred in the clodronate group, while the spine radiographies revealed 2 new fractures and a worsening of 2 pre-existent fractures in controls. An improvement in VAS back pain score was observed in the clodronate group (from $4.3 \pm 2.7$ to $2.9 \pm 2.0 ; \mathrm{P}<0.05$ ) but not in controls (from $4.4 \pm 3.1$ to $4.2 \pm 3.4 ; \mathrm{P}=\mathrm{NS}$ ).

After 2 years, spine BMD was $1.92 \%$ higher in patients who received clodronate compared to placebo $(\mathrm{P}<0.0001)$ and total hip BMD was $1.29 \%$ higher $(\mathrm{P}=0.002$ vs. placebo). Patients who received clodronate had a median $26 \%$ reduction in levels of serum PINP after 2 years of therapy, compared to an increase in patients on placebo $(\mathrm{P}<0.0001)$. Early changes in PINP were associated with changes in BMD and the likelihood of developing bone metastases. 


\section{COPYRIGHT $^{\circledR} 2018$ EDIZIONI MINERVA MEDICA}

poorly to BPs commonly used to treat osteoporosis, especially when they are used at the dosing regimens approved. This issue has been clearly demonstrated in randomized-controlled trials with zoledronic acid in patients presenting with thalassemia-associated osteoporosis, in which higher dosing regimens were used to achieve significant effects on the bone mineral density. Unfortunately, the safety of these dosing regiments has not been established. In this context, clodronate demonstrated to maintain the BMD, reduce the bone turnover markers and improve bone pain in patients presenting with thalassemia and low bone mass, with a good profile of safety and tolerability. ${ }^{54}$ These findings were not confirmed in another study 55 that has evaluated the effects of long-term cyclical clodronate therapy (300 mg i.v. every 3 weeks for 2 years) and of an active placebo (calcium and vitamin D) on bone mass and bone turnover in 30 male patients with beta-thalassemia major, in which no increases in areal bone density were observed.

\section{Effects of clodronate in neoplastic diseases}

In recent years, the role of BPs in the management of neoplastic diseases has expanded. The rationale for use of antiresoptive therapies in oncology is based on their effects in preventing complications related to bone metastases in different types of cancer (mainly breast and prostate cancer), their inhibitory action on osteolysis that can limit bone marrow invasion and the survival of any inactive cancer cells in the micro-environment of the bone marrow, and their inhibitory action on osteopenia and osteoporosis caused by anti-neoplastic hormones and chemotherapies. Several trials have shown that BPs reduces the risk of skeletal events and delay the time to skeletal events, and may also reduce bone pain and improve quality of life in patients with metastatic breast cancer or other types of cancer. ${ }^{56}$ In most of these trials Authors evaluated, as a secondary endpoints, the positive effects of BPs on the BMD and markers of bone turnover, demonstrating that BPs may be useful in preventing "cancer-treatment induced bone loss" (CTIBL).

In this context, the role of oral clodronate in the management/prevention of CTIBL has been well established. It is interesting to note that, in these trials, the dosing regimen of oral clodronate used was greater $(1600 \mathrm{mg} /$ day $)$ compared to that usually prescribed for the management of postmenopausal osteoporosis $(800 \mathrm{mg} / \mathrm{day})$, being doubled. In an earliest trial, ${ }^{37} 67$ women with relapsing breast cancer were treated with oral clodronate $1600 \mathrm{mg} /$ day for 8 months or acted as untreated controls. Treatment with clodronate increased BMD at lumbar spine and other skeletal sites, compared to decreases in the control group, and was associated with more marked increases of BMD in woman without evident lumbar spine bone metastases.

When given in addition to antiestrogen therapy in patients with early stage breast cancer oral clodronate $1.6 \mathrm{~g} /$ day significantly increased BMD in the lumbar spine and femoral neck, compared to no significant changes in BMD in the control group of patients given anti-oestrogens only. ${ }^{38} \mathrm{At}$ the follow-up at 3 and 5 years, ${ }^{42}$ clodronate was confirmed to be able to retard, but not to totally prevent, the bone loss related to the withdrawal of hormone replacement therapy, especially in lumbar spine. In the extended 10-years follow-up in 268 patients, ${ }^{49} 3$ of 41 patients in the clodronate group, and 11 of 48 in the control group, developed spinal osteoporosis, with similar rates with hip osteoporosis. The 10-year spinal osteoporosis-free survival rate was significantly higher in the clodronate group than in the control group.

In another study ${ }^{39}$ with oral clodronate $1.6 \mathrm{~g} /$ day given in addition to chemotherapy in 148 premenopausal women with primary breast cancer and absence of skeletal metastases treatment with clodronate significantly reduced bone loss at 2 years caused by chemotherapy-induced ovarian failure. In the follow-up at 3 and 5 years, i.e. 2 years after the end of therapy, ${ }^{43}$ the bone loss was still significantly less in the clodronate group compared with the control group receiving chemotherapy only.

In a subgroup analysis of a large, placebo-controlled study in 851 women with primary breast cancer, ${ }^{51}$ clodronate $1600 \mathrm{mg}$ /day for 2 years was associated with increased BMD at lumbar spine and total hip, with reduced bone turnover and protection against bone metastases, compared to placebo. Effects on BMD persisted for up to 3 years post-treatment. 


\section{COPYRIGHT $^{\circledR} 2018$ EDIZIONI MINERVA MEDICA}

There is less evidence of efficacy with the use of the i.v. route of administration of clodronate in women with breast cancer. In 45 premenopausal women with early stage breast cancer 467 cycles of i.v. clodronate $1500 \mathrm{mg}$ had limited effects in the prevention of bone loss related to chemotherapy-induced ovarian failure.

With regard to prostate cancer, it is well established that a rapid loss of BMD occurs within the first 6 to 12 months of androgen-deprivation therapy ${ }^{57}$ and that BPs therapy is effective in increasing BMD and reducing the incidence of pathological fractures in prostate cancer patients on androgen deprivation therapy. ${ }^{58}$ In a study ${ }^{48}$ performed to evaluate the effects of androgen deprivation therapy in promoting osteoporosis or osteopenia, 94 prostatectomized men with rising prostate-specific antigen were randomized to receive i.v. clodronate $1500 \mathrm{mg}$ every month, i.v. zoledronic acid $4 \mathrm{mg} / \mathrm{month}$, or placebo, for 36 months. A progressive bone loss was observed in the untreated 31 patients, who developed osteoporosis or osteopenia, compared with small decreases in BMP and fewer cases of osteoporosis in patients treated with clodronate or zoledronate. The protective effect in BMD loss at 18 months was significantly higher with clodronate than with zoledronate. This study showed that i.v. BPs (and particularly clodronate) have a protective effect in patients undergoing androgen deprivation therapy.

In conclusion, clodronate demonstrated to be effective in the management of several different types of secondary osteoporosis, producing beneficial effects on the BMD and bone turnover, comparable to that reported in postmenopausal and elderly women in which the anti-fracture efficacy of clodronate has been established. It is however interesting to note that in some of these conditions (CTIBL) clodronate demonstrated its efficacy at doses superior than those commonly used (1600 mg/day versus $800 \mathrm{mg} /$ day).

The use of clodronate in bone marrow edema syndromes

The bone marrow edema (BME) syndrome can be defined as a clinico-radiological entity in which transient non-specific subacute or chronic joint pain, predominantly of the hip and knee, is associated with characteristic MRI appearances, in the absence of specific signs of avascular necrosis, antecedent trauma or infection. 59

The classification of BME is based on the presence or absence of risk factors. Primary BME is diagnosed without an identifiable underlying cause, whereas secondary BME syndrome may be due to other conditions, such as degenerative or inflammatory rheumatic diseases, ischemic insults, infections, neoplasia, iatrogenic effects, metabolic diseases or neurological conditions. ${ }^{60}$

The complex regional pain syndrome (CRPS), a severely disabling pain syndrome characterized by sensory and vasomotor disturbance, edema and functional impairment, sometimes developing following a trauma or surgery, is included among the BME syndromes. Typically, a single extremity is affected, and the syndrome may develop in the setting of major nerve injury (CRPS type II) or in the absence of such injury (CRPS type I). ${ }^{61}$ In at least $10 \%$ of cases, it is not possible to identify an event correlated with the disease. In addition to the typical MRI finding of BME, other possible CRPS radiological features are a patchy or diffuse osteoporosis in the painful region and the enhanced radionuclide uptake on bone scintigraphy. ${ }^{62}$

BPs are the drug class with the best profile of efficacy in the treatment of CRPS. Their use in CRPS patients was originally based on their analgesic properties, which are well documented in a variety of bone and joint disorders, as well as in other painful situations unrelated to bone and joint diseases. ${ }^{63}$ The effects of BPs on pain may be attributable to their ability to inhibit the production of prostaglandins, lactic acid, and/or various neuropeptides and neuromodulators, all of which are possibly involved in the sensitization of afferent nerve fibres and pain modulation. ${ }^{64}$ In patients with CRPS, BPs may also interfere with the pathogenic pathway triggered by the mononuclear-phagocyte lineage locally activated by tissue injuries by an inhibition of proliferation, activation and viability of monocytes and macrophages, by decreasing the production of TNF- $\alpha$ and other proinflammatory cytokines and by the inhibition of keratinocyte proliferation and growth. 62

Over the past few decades, the results of several clinical trials have suggested the potential 


\section{COPYRIGHT $^{\circledR} 2018$ EDIZIONI MINERVA MEDICA}

beneficial effects of BPs in reducing pain and improving physical function in patients with CRPSI. ${ }^{65}$ The BPs efficacy is greater when therapy is started in early stages of disease and this confirms their ability to contrast the phlogistic processes, which are predominant in the first phase of CRPS. ${ }^{62}$

Table III ${ }^{66,67}$ summarizes the results of studies with clodronate in the treatment of BME syndromes.

In a randomized, double blind, placebo-controlled study, 6632 patients with CRPS-I were randomized to receive either i.v. clodronate 300 $\mathrm{mg} /$ day for 10 consecutive days or placebo; 40 days later, the placebo treated patients received the clodronate treatment. The evaluation of efficacy was based on a visual analogue scale of pain (VAS, range 0-100), the clinical global assessment (CGA, range 0-3) and an efficacy verbal score (EVS, range 0-3). Clinical and biochemical assessments were performed before the treatment, 40, 90 and 180 days later. Forty days after treatment, subjects receiving clodronate showed significantly improved VAS, CGA and EVS score compared with controls $(\mathrm{P}<0.001$ between groups in all parameters). These improvements were further sustained after 180 days from the start of treatment. When clodronate infusions were administered to patients who had previously received placebo, significant differences ad day 40 were observed in comparison with values measured 40 days of treatment with placebo. In comparisons with the results obtained in a randomized, double-blind placebo-controlled study that tested the efficacy of neridronate in CRPS, 68 the improvements of clinical parameters in patients treated with clodronate were comparable to those reported with neridronate.

The effects of clodronate and neridronate in the treatment of CRPS were directly compared in another study, ${ }^{67}$ in which 18 patients with femoral head algodystrophy were randomized to receive i.v. clodronate $300 \mathrm{mg}$ for 12 days or i.v. neridronate $100 \mathrm{mg}$ given four times in 10 days. Efficacy was evaluated by means of a VAS for pain, clinical score, bone turnover markers (urinary NTx/creatinine ratio, alkaline phosphatase and osteocalcin) and radiological findings. Both drugs were effective, but the improvements of clinical, laboratory and radiological parameters were more rapid in patients treated with neridronate than those observed in the clodronate group.

The results of the above clinical studies indicate that treatment with i.v. clodronate in patients with CRPS is associated with clinically relevant and persistent benefits. However, the results of the comparison with neridronate suggest that a global dose of $3000 \mathrm{mg}$ may be inadequate for the treatment of CRPS and that, therefore, a higher dose may be needed to maximise clinical response.

\section{Clodronate in the treatment of osteoarthritis}

The real pathogenesis of OA is still unclear and the question whether $\mathrm{OA}$ is a disease affecting bone, cartilage or both, is still unanswered. There are data suggesting that not only cartilage is in-

TABLE III.--Results of studies with clodronate in bone marrow edema syndromes.

\begin{tabular}{|c|c|c|}
\hline Reference & $\begin{array}{c}\text { Diagnosis } \\
\text { N. of patients }\end{array}$ & Treatment groups, dose regimen and duration \\
\hline Varenna et al., $2000^{66}$ & $\begin{array}{c}\text { CRPS-I } \\
32\end{array}$ & $\begin{array}{l}\text { A) i.v. clodronate } 300 \mathrm{mg} \text { daily for } 10 \text { days } \\
\text { B) i.v. placebo daily for } 10 \text { days, then (at day } 40 \text { ) clodronate } 300 \mathrm{mg} \text { daily for } \\
10 \text { days }\end{array}$ \\
\hline
\end{tabular}

$\begin{array}{ccc}\text { Muratore } \text { et al. } 200467 & \begin{array}{c}\text { Femoral head } \\ \text { algodystrophy }\end{array} & \text { A) i.v. clodronate } 300 \mathrm{mg} \text { daily for } 12 \text { days } \\ 18 & \text { B) i.v. neridronate } 100 \mathrm{mg} \text { in } 4 \text { administrations over } 10 \text { days }\end{array}$

CRPS-I: complex regional pain syndrome type I; i.v.: intravenous; VAS: Visual Analogue Scale; CGA: clinical global assessment; EVS: efficacy verbal score; NTX: N-terminal telopeptide. 


\section{COPYRIGHT $^{\circledR} 2018$ EDIZIONI MINERVA MEDICA}

volved in the development of OA, as the subchondral bone seems to play a crucial role in the pathogenesis of the disease. These data represent a very important change in the study of OA as originally it was proposed that OA was protective for osteoporosis and viceversa. ${ }^{69}$

The role of BPs in the management and in the prevention of OA is still under debate. BPs are commonly used as antiosteoporotic drugs because of their ability to inhibit bone resorption, and this could be the rationale for its use. There are papers showing that in surgical and animal models BPs are able to protect bone and cartilage from pathological changes. In clinical setting risedronate showed positive effects on joint structure in OA, but there are no data showing the ability of BPs to slow the progression of the disease. ${ }^{69}$

A recent meta-analysis ${ }^{70}$ that has examined the results of 13 studies including 3823 participants in order to evaluate the effects of BPs in the treatment of OA pain (8 studies in OA of the knee, 1 of the hand, 3 of the spine and 1 of the hip), concluded that there is limited evidence that BPs are effective in the treatment of OA pain. In particular, two of these studies involving more than 2000 patients with knee OA were not able to demonstrate the efficacy of risedronate on the OA pain. However, only two studies with clodronate were included in the meta-analysis 71,72 and both of them were indicative of positive effects of clodronate in OA pain.

The search in literature has found 5 published papers that have evaluated the efficacy and safe- ty of clodronate in the treatment of hand and knee OA (Table IV). ${ }^{71-75}$ Two published articles have shown that clodronate is effective for painful erosive OA of the hands. In the first one, ${ }^{74}$ 29 patients were treated with i.v. clodronate 300 mg for 7 days. Treatment was repeated every 3 months for a total number of 73 cycles, and was associated with a significant reduction in pain measured with VAS score $(\mathrm{P}=0.0001)$. Clodronate also determined an increase of strength of the hands and a significant decrease from baseline in the number of painful joints.

In the second study, ${ }^{72} 24$ patients were treated with i.v. clodronate $300 \mathrm{mg}$ for 7 days as attack dose, followed by i.m. clodronate $100 \mathrm{mg}$ for 14 days every three months and by a 24-month follow-up. A control group of 14 patients received hydroxyl-chloroquine $400 \mathrm{mg}$ daily for 30 days, followed by $200 \mathrm{mg}$ daily for the next 11 months. Treatment with clodronate was associated with a significant reduction in pain $(\mathrm{P}<0.001)$, Dreiser score $(\mathrm{P}=0.012)$ and number of tender joints $(\mathrm{P}=0.0011)$, as well as with significant improvements of strength of right $(\mathrm{P}=0.04)$ and left $(\mathrm{P}=0.016)$ hands, physician's global assessment $(\mathrm{P}<0.001)$ and patient's global assessment $(\mathrm{P}=0.021)$. Treatment with hydroxyl-chloroquine was ineffective and of poor patients' acceptance.

Other 3 studies have shown that intraarticular (i.a.) clodronate is effective in the management of knee OA. The effects of 6 i.a. injections of clodronate $0.9 \mathrm{mg}$ on pain and synovial fluid concentration of inflammatory mediators were evaluated in 20 patients with synovitis secondary

\section{Results of efficacy}

At 40 days from the start of treatment, patients randomized to clodronate had significant decreases of pain VAS and CGA $(\mathrm{P}=0.002$ and $\mathrm{P}=0.001$, respectively). Compared with the placebo group, significant differences were found in all clinical variables (VAS: $\mathrm{P}=0.001$; $\mathrm{CGA}$ : $\mathrm{P}=0.001$; EVS.: $\mathrm{P}<0.0001$ ). When clodronate was given to patients who received placebo in the double blind phase, all variables significantly improved compared to values measured after 40 days with placebo. Pooling the results of all 32 patients after clodronate treatment, at day 180 the overall percentage decrease of VAS was $93.2 \% \pm 15.6 \%$, with 30 patients significantly improved or asymptomatic.

In both treatment groups, NTX, alkaline phosphatase and osteocalcin levels at 30 days of treatment were indicative of the reduction of bone turnover; however, in the neridronate group changes from baseline were statistically significant from Day 15. Although the radiological assessment showed a decrease of bone rarefaction in both groups, complete healing of femoral head was significantly more marked in patients treated with neridronate than in those treated with clodronate. Pain decrease and functional recovery were observed in both groups, more markedly in the neridronate group. 


\section{COPYRIGHT $^{\circledR} 2018$ EDIZIONI MINERVA MEDICA}

TABLE IV.-Results of studies with clodronate in the treatment of osteoarthritis.

\begin{tabular}{|c|c|c|}
\hline Reference & $\begin{array}{l}\text { Diagnosis } \\
\text { N. of patients }\end{array}$ & Treatment groups, dose regimen and duration \\
\hline Cocco et al., 199973 & $\begin{array}{l}\text { OA of the knee } \\
20\end{array}$ & i.a. clodronate $0.9 \mathrm{mg}$ on day $1,3,7,10,14$ and 21 \\
\hline Saviola et al., $2000^{74}$ & $\begin{array}{l}\text { OA of the hand } \\
29\end{array}$ & i.v. clodronate $300 \mathrm{mg}$ every 3 months ( 73 cycles in total) \\
\hline Rossini et al., $2009^{71}$ & $\begin{array}{c}\text { OA of the knee } \\
145\end{array}$ & $\begin{array}{l}\text { A) i.a. clodronate } 0.5 \mathrm{mg} \text { weekly for } 4 \text { weeks } \\
\text { B) i.a. clodronate } 1 \mathrm{mg} \text { weekly for } 4 \text { weeks } \\
\text { C) i.a. clodronate } 2 \mathrm{mg} \text { weekly for } 4 \text { weeks } \\
\text { D) i.a. clodronate } 1 \mathrm{mg} \text { two injections/week for } 2 \text { weeks } \\
\text { E) Hyaluronic acid } 20 \mathrm{mg} \text { weekly for } 4 \text { weeks }\end{array}$ \\
\hline Saviola et al., $2012^{72}$ & $\begin{array}{l}\text { OA of the hand } \\
\qquad 38\end{array}$ & $\begin{array}{l}\text { A) i.v. clodronate } 300 \mathrm{mg} \text { for } 7 \text { days, followed by i.m. clodronate } 100 \mathrm{mg} \text { /day } \\
\text { for } 14 \text { days every } 3 \text { months, for a total of } 24 \text { months } \\
\text { B) Hydroxychloroquine } 400 \mathrm{mg} \text { daily for } 30 \text { days, followed by } 200 \mathrm{mg} \text { daily } \\
\text { for the next } 11 \text { months }\end{array}$ \\
\hline Rossini et al., $2015^{75}$ & OA of the knee & $\begin{array}{l}\text { A) i.a. clodronate } 2 \mathrm{mg} \text { weekly for } 4 \text { weeks } \\
\text { B) i.a. placebo weekly for } 4 \text { weeks }\end{array}$ \\
\hline
\end{tabular}

OA: osteoarthritis; i.a.: intraarticular; VAS: visual analogue scale; i.v.: intravenous; NS: not significant; i.m.: intramuscular; WOMAC: Western Ontario MacMaster.

to knee OA. ${ }^{73}$ Treatment with clodronate led to a significant reduction in spontaneous pain and pain on active movement $(\mathrm{P}<0.05)$, which was correlated with the clodronate-induced reduction in prostaglandin E2 levels.

In another study, ${ }^{71} 145$ patients with knee OA were divided in 5 groups and were treated with i.a. clodronate at different doses $(0.5 \mathrm{mg} / \mathrm{week}$ for 4 weeks, $1 \mathrm{mg}$ /week for 4 weeks, $2 \mathrm{mg}$ /week for 4 weeks, $1+1 \mathrm{mg} /$ week for 2 weeks) or with i.a. hyaluronic acid $20 \mathrm{mg} /$ week for 4 weeks. In this study, weekly i.a. clodronate was at least as effective as hyaluronic acid in symptomatic and functional improvements of knee OA, as measured by means of a VAS for pain and the Lequesne index. In patients treated with clodronate, a significant $(\mathrm{P}=0.03)$ linear trend for a dose-response relationship was found for active movement VAS pain.

In the third study, 7580 patients with knee OA were treated with weekly i.a. clodronate 2 $\mathrm{mg}$ or matched placebo for 4 weeks, followed by 12 weeks of follow-up. Five weeks after the last injection, a significant reduction in pain was observed in the clodronate group compared to placebo $(\mathrm{P}<0.05)$. Moreover, Lequesne Index,
Western Ontario MacMaster (WOMAC) pain subscale, global knee OA evaluation from both patients and investigators significantly improved in the clodronate group. Finally the acetaminophen consumption decreased in patients treated with clodronate $(\mathrm{P}<0.05)$ compared to placebo.

A recent paper ${ }^{13}$ has shown that in-vitro clodronate exerts an anabolic effect on articular chondrocytes mediated through the purinergic receptor pathway. In particular, clodronate is able to produce in the cartilage an increasing accumulation of ECM by $90 \%$ after 4 weeks of culture and without an associated effect on matrix turn-over. The findings support the previous clinical evidence and suggest that clodronate may be useful as adjunctive therapies to potentially ameliorate progression of cartilage degeneration and improve the management of OA.

\section{The use of clodronate in orthopedic surgery}

Clodronate is largely used in the treatment of fracturative complications of osteoporosis that are treated surgically (osteosynthesis or prosthetic replacement) or not-invasively (reductioncontention in external tutorials). In the field of 


\section{COPYRIGHT $^{\odot} 2018$ EDIZIONI MINERVA MEDICA}

Statistically significant reductions $(\mathrm{P}<0.05)$ of spontaneous pain and pain on active movement, evaluated by a 100-mm VAS, were observed at end of treatment. The decrease of pain was correlated with the clodronate-induced reduction of prostaglandin E2 levels.

Mean VAS for pain decreased from $5.63 \pm 2.14$ to $2.93 \pm 1.95$ ( $\mathrm{P}=0.0001)$; the pain reduction lasted for a mean of 88.33 days. Strength of the hands $(\mathrm{mmHg})$ was measured in 16/73 cycles and increased on the right from $169.38 \pm 75.85$ to $190.31 \pm 81.76$, and on the left from $180.56 \pm 68.27$ to $196.11 \pm 85.55$ ( $\mathrm{P}=\mathrm{NS}$ ). The number of painful joints decreased from $4.75 \pm 2.52$ to $2.56 \pm 1.93(\mathrm{P}=0.0011)$, and the number of swollen joints decreased from $3.07 \pm 2.69$ to $2.67 \pm 2.61(\mathrm{P}=\mathrm{NS})$.

VAS for different types of pain and the Lequesne index significantly improved in all treatment groups after the first injection and continued to improve even 2-4 weeks after the last injection without significant difference among the groups. A significant $(\mathrm{P}=0.03)$ linear trend for a dose-response $(0.5-2 \mathrm{mg}$ clodronate) relationship was found for active movement VAS pain. Both joint extension and mobility scores improved significantly at all time points in all treatment groups without statistical differences among them.

Patients in group A had significant improvements in pain reduction $(\mathrm{P}<0.001)$, Dreiser's score $(\mathrm{P}=0.012)$, number of tender joints $(\mathrm{P}=0.011)$, strength of right $(\mathrm{P}=0.04)$ and left $(\mathrm{P}=0.016)$ hands, physician's global assessment $(\mathrm{P}=0.001)$, and patient's global assessment $(\mathrm{P}=0.021)$. In group $\mathrm{B}, 8 / 14$ hydroxychloroquine was ineffective and enrolment was stopped.

A significant difference in favour to clodronate in VAS for pain was observed 5 weeks after the last injection (-114.6 vs. -87.2 for clodronate and placebo group, respectively; $\mathrm{P}<0.05)$. The improvements in Lequesne index, global knee OA evaluation from both patients and investigators, and the WOMAC pain subscale were significantly greater in the clodronate group. The proportion of patients that did not require acetaminophen was significantly greater in the clodronate group (about $10 v \mathrm{vs} .30 \%$ for clodronate and placebo group, respectively; $\mathrm{P}<0.05)$.

orthopedic surgery, clodronate may be indicated in subjects undergoing prosthesis surgery, either in the management of the peri-prosthetic osteogenesis, starting from the pre-operative phase and the immediate post-surgery, or in the treatment of osteolysis in case of aseptic loosening due to wear debris disease.

As a consequence of the reparative osteogenesis (i.e. the bone growth and periprosthetic bone remodeling) that follows the damage of the cartilage-bone interface and the bone remodeling, a decrease in BMD in the first 3 months postsurgery is a common finding in joints that are subject to prosthesis implant. It has been shown ${ }^{76}$ that the loss of BMD after total hip replacement is not paralleled by similar decreases in other body regions (lumbar spine, radius, contralateral hip). The loss in BMD is of mechanical origin and correlated with the stress-shielding phenomena. ${ }^{77}$ It may vary between $3 \%$ and more than $15 \%$, and is generally recovered within 24 months. 78

Treatment with antiresoptive agents may counteract the underlying osteometabolic damage, may attenuate the periprosthetic loss due to stress-shielding and ultimately may contribute to the anabolic recovery, as demonstrated in experimental models and in clinical trials. ${ }^{79}$

In vitro studies in ovariectomized rats ${ }^{80}$ have demonstrated that pre-surgery treatment with BPs increases the BMD of the cancellous bone and the stability of hydroxyapatite-coated implants. In the dog model, the early administration of BPs had no significant influence on the extent of bone apposition, the extent or thickness of the hydroxyapatite coating, or the cortical or trabecular bone area around the implants. ${ }^{81}$

Several clinical trials have documented the use of BPs in the postimplant phase to prevent the BMD loss and to enhance the osteogenesis around the prosthesis components. A metaanalysis of 6 randomized controlled trials ${ }^{82}$ suggested that BPs have a beneficial effect in maintaining periprosthetic BMD, while another meta-analysis based on 14 randomized controlled trials $^{83}$ has shown that the protective effect of BPs could persist up to 70 months after surgery and after drug discontinuation. The prevention of femoral periprosthetic bone loss following total hip arthroplasty achieved by postoperative antiresorptive treatment with BPs has been documented up to six years of follow-up. ${ }^{84}$ In 


\section{COPYRIGHT $^{\circledR} 2018$ EDIZIONI MINERVA MEDICA}

addition to their use by oral or i.m. route, the addition of BPs to acrylic bone cement is able to stimulate the periprosthetic osteogenesis by inhibiting the bone resorption due to osteoclastogenesis. ${ }^{85}$

The effects of the oral, i.m. and i.v. administration of clodronate in orthopedic surgery have been tested in studies conducted in patients undergoing total knee or hip arthroplasty (Table V). ${ }^{86-90}$ In the first of these studies, ${ }^{86}$ oral clodronate $1600 \mathrm{mg}$ daily, administered for 3 weeks before until 6 months after a total knee replacement with a cemented implant, significantly reduced early prosthetic migration. The results at 4 years in the same group of patients ${ }^{87}$ showed an almost statistically significant difference between the clodronate and the placebo groups in changes from baseline of maximal total point motion (MTMP), with the clodronate group showing $25 \%$ less migration than placebo. From 1 to 4 years, there was a continuous increase in rotation around the transverse axis in the controls, which differed from the clodronate group.

The effects of i.m. clodronate in the periprosthetic bone remodeling were studied in 21 patients operated with uncemented femoral hip implants. ${ }^{88}$ Clodronate $100 \mathrm{mg}$ i.m. was given daily during the first week, then every week for 6 months and every 2 weeks for the next 6 months. At the 1-year follow-up, treatment with clodronate was associated with a significant less decrease of BMD at the medial metaphyseal region, and at both medial and lateral diaphyseal regions, compared to untreated controls.

In another study, 89 in which 13 patients undergoing cementless total hip arthroplasty were treated postoperatively either with clodronate $3600 \mathrm{mg}$ i.v. in four months (a total loading dose of $1800 \mathrm{mg}$ postoperatively infused over two hours on two consecutive days and then 900 mg every 2 months after the surgery) or with placebo, clodronate prevented the BMD loss at proximal femur and the pelvis and significantly improved circulating levels of C-terminal telopeptide of type I collagen (ICTP) compared to placebo.

The efficacy of i.m. clodronate $100 \mathrm{mg}$ /week given for 12 months to reduce bone loss around uncemented stems after total hip arthroplasty was demonstrated in another study that included 91 patients..$^{90}$ At the end of treatment, clodronate determined a significant reduction of bone loss,

TABLE V.-Results of studies with clodronate in orthopedic surgery.

\begin{tabular}{lcll}
\hline Reference & $\begin{array}{c}\text { Diagnosis } \\
\text { N. of patients }\end{array}$ & Treatment groups, dose regimen and duration \\
\hline Hilding et al., 200086 & Knee prosthesis & C) Oral clodronate $1600 \mathrm{mg}$ daily from 3 weeks before to 6 months after surgery \\
& 50 & D) Placebo from 3 weeks before to 6 months after surgery
\end{tabular}

Hilding et al., $2006^{87}$ Knee prosthesis A) Oral clodronate $1600 \mathrm{mg}$ daily from 3 weeks before to 6 months after surgery $\begin{array}{lll}\left(4-y e a r \text { follow-up of }{ }^{86} \text { ) }\right. & 47 & \text { B) Placebo from } 3 \text { weeks before to } 6 \text { months after surgery }\end{array}$
Massari et al., $2002^{88} \quad$ Hip arthroplasty A) i.m. clodronate $100 \mathrm{mg}$ daily during the first week, then every week for 6 21 months and every 2 weeks for the next 6 months
B) Untreated control group
Resch et al., $200789 \quad$ Hip arthroplasty A) i.v. clodronate $3600 \mathrm{mg}$ in 4 months (a total loading dose of $1800 \mathrm{mg}$
13 postoperatively in two consecutive days and then $900 \mathrm{mg}$ every two months after surgery)
B) Placebo at the same regimen of clodronate
Trevisan et al., 201090 Hip arthroplasty A) i.m. clodronate $100 \mathrm{mg}$ weekly for 12 months
91 B) Untreated control group

MTMP: maximum total point motion; i.m.: intramuscular; BMD: bone mineral density; i.v.: intravenous; ICTP: C-terminal telopeptide of type I collagen. 


\section{COPYRIGHT $^{\odot} 2018$ EDIZIONI MINERVA MEDICA}

with increased effects observed in the female population, which is at higher risk for bone loss.

The current evidence suggests that, while approaching the prosthetic surgery of a joint affected by osteoarthritis, the metabolic damage of the iuxta-articular bone is carefully considered to optimize the complete treatment of osteoarthritis in all its components. Therefore, it is important that the joint is adequately prepared for the surgery, which will cause an immediate postsurgical bone loss, as well as in the bone remodeling osteointegration process that follows the intervention. The antiresorptive effect, the bone remodeling modulation, the anti-inflammatory and analgesic effects of clodronate, all are properties that are helpful in the management of patients undergoing orthopedic surgery.

\section{Safety of clodronate}

Clodronate in generally well tolerated in any route of administration (oral, i.m., i.v. and i.a.) and is devoid of high-risk contraindications. ${ }^{91} \mathrm{In}$ $2-10 \%$ of cases, gastrointestinal symptoms such as nausea and dyspepsia develop and have been usually observed in people taking the drug orally and at high doses. ${ }^{16}$ However, parenteral (i.v. and i.m.) formulations of clodronate have not been associated with gastrointestinal effects. There are no clinically significant effects of oral clodronate on hematological or biochemical indices of safety. ${ }^{27,30}$

All BPs are eliminated via renal route. Renal failure has been reported with administration of parenteral BPs, especially when administered i.v. at high doses and high infusion rates, as reported for zoledronic acid. ${ }^{92}$ Clodronate is not contraindicated in patients with renal failure and, although its safety in this special population should be further clarified, several data suggest that clodronate may be used also in patients with decreased renal function. However, clodronate should be administered with care in patients with renal impairment and the dose should be modified according to renal function, ${ }^{16}$ to be monitored before and during treatment.

In recent years, cases of osteonecrosis of the jaw in patients receiving BPs therapy have been reported in literature, mostly in patients receiving the i.v. amino-BPs zoledronic acid and pamidronic acid. ${ }^{93}$ As clodronate is a NNBP with a different mechanism of action from that of NBPs, osteonecrosis of the jaw has been observed only rarely in patients treated with clodronate and

Results of efficacy

Clodronate reduced prosthetic migration, as measured by MTPM, from $0.40 \mathrm{~mm}$ to $0.29 \mathrm{~mm}(\mathrm{P}=0.01 \mathrm{vs}$. placebo).

At 4-year follow-up, the average migration (MTPM) at 4 years from the postoperative examination was $0.43 \pm 0.14 \mathrm{~mm}$ in the clodronate group and $0.58 \pm 0.33 \mathrm{~mm}$ in the placebo group ( $\mathrm{P}=0.06$ between groups). Rotation around the transverse axis (backward tilting) was $0.37 \pm 0.48^{\circ}$ in the placebo group and $0.02 \pm 0.18^{\circ}$ in the clodronate group ( $\mathrm{P}=0.002$ between groups). From 1 to 4 years, there was no difference in MTPM, but there was a continuous increase in rotation around the transverse axis in the controls, which differed from the clodronate group.

There was a significant less decrease of BMD in the clodronate group compared to controls: the differences were statistically significant for the medial metaphyseal region (-9.82\% vs. $-25 \%$ at 1 year) and for the diaphyseal regions, both medial (-7.87\% vs. $-9.35 \%)$ and lateral (-6.41\% vs. $-9.58 \%)$.

The mean change from baseline in BMD of the proximal femur and the pelvis were $+0.07 \%$ and $+0.03 \%$ in clodronate group, and $-0.02 \%$ and $-0.03 \%$ in the placebo group, respectively (NS between groups). Changes from baseline of ICTP and osteocalcin were $-0.07 \%$ and $-1.51 \%$ in the clodronate group, and $+0.22 \%$ and $+5.48 \%$ in the placebo group, respectively ( $\mathrm{P}<0.05$ between groups for ICTP and $0.05<\mathrm{P}<0.10$ for osteocalcin.

At month 12, patients treated with clodronate had less bone loss at almost all zones, reaching statistical significance $(\mathrm{P}<0.05)$ in Gruen zones 2 and 6 (difference of 6.6 and 5.9\%, respectively). The difference between groups was more marked in women than in men. Median percent changes in serum levels of markers of bone metabolism by gender were consistent with BMD changes. 


\section{COPYRIGHT $^{\circledR} 2018$ EDIZIONI MINERVA MEDICA}

mainly in patients who have a history of treatment with an amino-BP. ${ }^{16,93}$

Skin rashes and other allergic reactions have been described, albeit rarely, in patients taking clodronate, as it has been the case for transitory and usually clinically silent hypocalcemia. ${ }^{17}$

Intramuscular injection of clodronic acid is associated with injection site pain or discomfort in some patients. ${ }^{23,} 32,33 \mathrm{~A}$ new i.m. formulation of clodronate containing $1 \%$ lidocaine has been recently developed in Italy to reduce the incidence and severity of these effects. When compared with reference clodronate formulations not containing lidocaine, ${ }^{94}$ the i.m clodronate/lidocaine formulation showed significant reduction of pain intensity upon injection and for up to 2 hours afterwards. With regard to the newly tested dose regimens of i.m. clodronate, the administration of twice the drug dosage in a week significantly improved the efficacy of the treatment without inducing serious adverse events. ${ }^{34}$

\section{Discussion}

This review has examined the available literature on the use of clodronate in the treatment and prevention of primary and secondary osteoporosis, and its potential role in other musculo-skeletal diseases.

A variety of clinical trials conducted over more than two decades have provided a strong level of evidence on the efficacy and safety of clodronic acid in the maintenance or improvement of BMD and in reduction of risk of fractures when given orally, i.m. or i.v. in patients with postmenopausal osteoporosis. Clodronate was also used with success in the prevention or treatment of different forms of secondary osteoporosis, including GIOP and bone mass loss due to neoplastic or endocrine diseases.

Clodronate has shown interesting anti-inflammatory and analgesic properties that may lead to beneficial effects of the drug on pain and inflammation. Studies in animal models highlighted a pain-relieving and antinociceptive effect of clodronate both at central and peripheral level that is independent from antifracture effect and is achieved at doses lower than those inducing anti-bone-resorptive effects. ${ }^{2}$ Furthermore, it has been shown that clodronate reduces the pain in osteoporotic patients with vertebral fractures. ${ }^{95}$ This analgesic effects is not shared with other NBPs such as alendronate and risedronate, but has been reported with i.v. pamidronate. ${ }^{66}$ However, it should be taken into consideration that the anti-inflammatory and analgesic effects of clodronate have been observed in small number of patients studied, using different modes of administration in different diseases, and results were not always consistent between studies. ${ }^{2}$ Therefore, further research is needed to better clarify the potential anti-inflammatory and analgesic effects of clodronate beyond its antiresorptive properties.

Moreover, recent research has shown that clodronate has protective and anabolic effects on the cartilage that may counteract the process of cartilage degradation that occurs in the progression of OA and rheumatoid arthritis. ${ }^{13,15}$ A variety of studies have shown that clodronate may be beneficial in patients with other bone and joint diseases, such as OAs and bone marrow edema syndromes (e.g. CPRS). Finally, clinical trials have shown a promising role for clodronate in subjects undergoing prosthesis surgery, either in the preparation for the surgery or in the postoperative bone remodeling phase.

However, the efficacy of clodronate in the OA, CPRS and postprosthetic surgeries has been investigated in trials that included small samples of patients, used different methods of assessment and routes of administration of clodronate, and generally did not include an active comparator. Therefore, caution should be used in the interpretation of the available preliminary results, which should be confirmed in large active-controlled clinical trials using robust outcome measures.

Different formulations and dose schedules of clodronate have been used over the years. In the management of postmenopausal osteoporosis, the efficacy of clodronate in increasing BMD and in reducing the risk of vertebral and nonvertebral fractures has been largely documented with both the oral and the parenteral (i.v. and i.m. formulations), with an acceptable safety profile. Notably, the positive effects of oral clodronate in cancer-induced bone loss have been observed at a doubling daily dose than that used in the management of postmenopausal osteoporosis. 


\section{COPYRIGHT $^{\circledR} 2018$ EDIZIONI MINERVA MEDICA}

A range of i.m. formulations of clodronate (without local anesthetic or with lidocaine) are currently approved in Italy. The availability of an i.m. formulation not requiring infusion over limited time frames, while allowing at the same time an intermittent administration, overcomes the limitations of the long-term daily treatment with the oral form, and hence the risk of gastrointestinal adverse effects. The intermittent administration offers important advantages compared with daily oral administration, resulting in potential improvement in compliance, and counteracts the problem of low bioavailability, further exacerbated by the intake of food and beverages. ${ }^{97}$ Importantly, clodronate and other BPs are characterized by a direct correlation between dose and densitometric effect. ${ }^{98}$ As it is widely accepted that a reduction in the dosing frequency of BPs may improve adherence and therefore therapeutic outcomes, ${ }^{99}$ an increase in the interval between consecutive administrations should be associated with a concomitant increase in the overall BPs dose received.

Studies show that the two formulations of clodronate now used in osteoporosis (i.m. and oral) are associated with similar increases in BMD, with slightly higher values for the i.m. formulation. ${ }^{16}$ Moreover, the i.m. formulation appears to be more effective than intermittent i.v. treatment. ${ }^{24}$

With regard to dose schedule, it has been suggested that the optimal interval between 2 consecutive administrations of i.m. clodronic acid may be 15-20 days, i.e. the time span of osteoclast activation. ${ }^{21,35}$ The "twice-a-month" regimen with $200 \mathrm{mg}$ i.m. clodronate improves adherence with the same clinical efficacy (in terms of BMD increase) and side-effect profile as weekly administration of $100 \mathrm{mg} .32,33$

With regards to the newly tested indications, further clinical studies involving larger cohorts are needed to optimize the dosage and length of therapy of clodronate in each clinical field in order to be able to maximize its properties on modulation of inflammation and bone remodeling. As an example, it is likely that the negative results on bone mass observed in one study in patients with thalassemia ${ }^{55}$ may be due to the low administered dose of clodronate ( $300 \mathrm{mg}$ i.v. every 3 weeks).

The recommended dose regimen of clodronate in the approved indications is well established in the Summary of Product Characteristics and in the information for prescription of the product. The proposed treatment regimens of clodronate in non-approved indications are summarized in Table VI and mainly reflect the experience of clinical trials. However, the dosage schemes tested in the available clinical trials might have led to suboptimal results and further trials are necessary for the definition of the most appropriate dosage of clodronate in each of the non-approved indication. As an example, the dose of i.v. clodronate used in the treatment of CRPS (i.e. a global dose of $3000 \mathrm{mg}$ given in 10 days) although effective, seem to be inadequate to maximise clinical response. With the availability of the $200 \mathrm{mg}$ i.m. formulation, a dose of $200 \mathrm{mg}$ for 10 days and then $200 \mathrm{mg}$ every other days for 20 days i.e. a cumulative dose of $4 \mathrm{~g}$ in a month (with

TABLE VI.--Proposed treatment regimens of clodronate in non-approved indications.

\begin{tabular}{|c|c|}
\hline Indication & Proposed treatment regimen \\
\hline Bone marrow edema syndromes (CPRS-I) & $\begin{array}{l}200 \mathrm{mg} \text { i.m. for } 10 \text { days and then } 200 \mathrm{mg} \text { i,m, every other days for } 20 \text { days i.e. a } \\
\text { cumulative dose of } 4 \mathrm{~g} \text { in a month (with possible repeated schemes in particular } \\
\text { cases) }\end{array}$ \\
\hline Osteoarthritis & $\begin{array}{l}300 \mathrm{mg} \text { i.v. for } 7 \text { days, followed by } 100 \mathrm{mg} / \text { day i.m. for } 14 \text { days every } 3 \text { months; } \\
\text { or } \\
2 \mathrm{mg} \text { i.a. weekly for } 4 \text { weeks }\end{array}$ \\
\hline Orthopedic surgery & $\begin{array}{l}1600 \mathrm{mg} \text { /day oral from } 3 \text { weeks before to } 6 \text { months after surgery; } \\
\text { or } \\
1800 \mathrm{mg} \text { i.v. postoperatively in two consecutive days and then } 900 \mathrm{mg} \text { i.v. every } \\
\text { two months after surgery) } \\
\text { or } \\
100 \mathrm{mg} / \text { day i.m. in the first week, then every week for } 6 \text { months and then every } 2 \\
\text { weeks for the next } 6 \text { months }\end{array}$ \\
\hline
\end{tabular}

CRPS-I: complex regional pain syndrome type I; i.v.: intravenous; i.m.: intramuscular; i.a.: intra-articular. 


\section{COPYRIGHT $^{\circledR} 2018$ EDIZIONI MINERVA MEDICA}

possible repeated schemes in particular cases) has been recently proposed.2 Similarly, further research is needed to define the optimal i.a. dose of clodronate and the length of treatment in the management of OA. In the study 69 that compared different dose regimens and schedules of i.a. clodronate in patients with knee OA, a dose-related affect was observed only in pain on movement, but not in pain at rest and mobility. Oral and parenteral (i.m. and i.v.) clodronate given at variable doses has also been evaluated in the management of patients undergoing knee and hip prosthesis, respectively.

The available studies have shown the positive effects of the i.a. administration of clodronate on the progression of cartilage degeneration in patients of OA. Taking into consideration that bone resorption and remodeling at unstable interfaces requires much higher doses of BPs than those used to inhibit an increased bone metabolism as in osteoporosis, ${ }^{100}$ the local i.a. clodronate administration at high doses may be useful to maximize the effectiveness in patients undergoing hip or knee prosthesis replacement.

Overall, clodronate had exhibited an acceptable safety and tolerability profile over the years in both the oral and parenteral formulations, and resulted to be at least as well tolerated as the other BPs. The good gastrointestinal tolerability of oral clodronate, the absence of systemic adverse effects with parenteral therapy and the lack of any deleterious action on bone mineralization, make clodronic acid a useful therapy for the management of osteoporosis and other musculoskeletal conditions.

\section{Conclusions}

In conclusion, the analysis of the available literature has shown that clodronate has important other effects beyond the antiresorptive activity. The analgesic, anti-inflammatory, bone- and chondro-modulating effects of clodronate have allowed its use in other musculoskeletal indications to those currently approved. Further research is needed to expand the potential place in therapy of clodronate and to define the optimal formulation and dose regimen in any of the tested new indications.

\section{References}

1. Russell RG. Bisphosphonates: mode of action and pharmacology. Pediatrics 2007;119(Suppl 2):S150-62.

2. Frediani B, Bertoldi I. Clodronate: new directions of use. Clin Cases Miner Bone Metab 2015;12:97-108.

3. Saviola G, Abdi-Ali L, Povino MR. Clodronate: old drug, new uses. J Biol Regul Homeost Agents 2015;29:719-22.

4. Russell RG, Watts NB, Ebetino FH, Rogers MJ. Mechanisms of action of bisphosphonates: similarities and differences and their potential influence on clinical efficacy. Osteoporos Int 2008; 19:733-59.

5. Rogers MJ. New insights into the molecular mechanisms of action of bisphosphonates. Curr Pharm Des 2003;9:2643-58.

6. Salo J, Lehenkari P, Mulari M, Metsikkö K, Väänänen HK. Removal of osteoclast bone resorption products by transcytosis. Science 1997;276:270-3.

7. Rogers MJ, Frith JC, Luckman SP, Coxon FP, Benford HL, Mönkkönen J, et al. Molecular mechanisms of action of bisphosphonates. Bone 1999;24(Suppl):73S-9S.

8. Frith JC, Mönkkönen J, Blackburn GM, Russell RG, Rogers MJ. Clodronate and liposome-encapsulated clodronate are metabolized to a toxic ATP analog, adenosine $5^{\prime}$-(beta, gamma-dichloromethylene) triphosphate, by mammalian cells in vitro. J Bone Miner Res 1997;12:1358-67.

9. Frith JC, Mönkkönen J, Auriola S, Mönkkönen H, Rogers MJ. The molecular mechanism of action of the antiresorptive and antiinflammatory drug clodronate: evidence for the formation in vivo of a metabolite that inhibits bone resorption and causes osteoclast and macrophage apoptosis. Arthritis Rheum 2001;44:2201-10.

10. Lehenkari PP, Kellinsalmi M, Näpänkangas JP, Ylitalo $\mathrm{KV}$, Mönkkönen J, Rogers MJ, et al. Further insight into mechanism of action of clodronate: inhibition of mitochondrial ADP/ATP translocase by a nonhydrolyzable, adeninecontaining metabolite. Mol Pharmacol 2002;61:1255-62.

11. Campagnoli C, Roberts IA, Kumar S, Bennett PR, Bellantuono I, Fisk NM. Identification of mesenchymal stem/ progenitor cells in human first-trimester fetal blood, liver, and bone marrow. Blood 2001;98:2396-402.

12. Tsuzaki M, Bynum D, Almekinders L, Faber J, Banes AJ. Mechanical loading stimulates ecto-ATPase activity in human tendon cells. J Cell Biochem 2005;96:117-25.

13. Rosa RG, Collavino K, Lakhani A, Delve E, Weber JF, Rosenthal AK, et al. Clodronate exerts an anabolic effect on articular chondrocytes mediated through the purinergic receptor pathway. Osteoarthritis Cartilage 2014;22:1327-36.

14. Dombrecht EJ, Schuerwegh AJ, Bridts $\mathrm{CH}$, Ebo DG, Van Offel JF, Stevens WJ, et al. Effect of bisphosphonates on nitric oxide production by inflammatory activated chondrocytes. Clin Exp Rheumatol 2007;25:817-22.

15. Wehling N, Palmer GD, Pilapil C, Liu F, Wells JW, Müller PE, et al. Interleukin-1 beta and tumor necrosis factor alpha inhibit chondrogenesis by human mesenchymal stem cells through NF-kappaB-dependent pathways. Arthritis Rheum 2009;60:801-12.

16. Frediani B, Cavalieri L, Cremonesi G. Clodronic acid formulations available in Europe and their use in osteoporosis: a review. Clin Drug Investig 2009;29:359-79.

17. Ghinoi V, Brandi ML. Clodronate: mechanisms of action on bone remodelling and clinical use in osteometabolic disorders. Expert Opin Pharmacother 2002;3:1643-56.

18. Giannini S, D'Angelo A, Malvasi L, Castrignano R, Pati T, Tronca R, et al. Effects of one-year cyclical treat- 


\section{COPYRIGHT $^{\circ} 2018$ EDIZIONI MINERVA MEDICA}

ment with clodronate on postmenopausal bone loss. Bone 1993; 14:137-41.

19. Filipponi P, Pedetti M, Fedeli L, Cini L, Palumbo R, Boldrini $\mathrm{S}$, et al. Cyclical clodronate is effective in preventing postmenopausal bone loss: a comparative study with transcutaneous hormone replacement therapy. J Bone Miner Res 1995; 10:697-703.

20. Giannini S, D’Angelo A, Sartori L, Passeri G, Dalle Carbonare L, Crepaldi G. Continuous and cyclical clodronate therapies and bone density in postmenopausal bone loss. Obstet Gynecol 1996;88:431-6.

21. Filipponi P, Cristallini S, Rizzello E, Policani G, Fedeli $\mathrm{L}$, Gregorio F, et al. Cyclical intravenous clodronate in postmenopausal osteoporosis: results of a long-term clinical trial. Bone 1996;18:179-84.

22. Heikkinen JE, Selander KS, Laitinen K, Arnala I, Väänänen HK. Short-term intravenous bisphosphonates in prevention of postmenopausal bone loss. J Bone Miner Res 1997; 12:103-10

23. Rossini M, Braga V, Gatti D, Gerardi D, Zamberlan N, Adami S. Intramuscular clodronate therapy in postmenopausal osteoporosis. Bone 1999;24:125-9.

24. Filipponi P, Cristallini S, Policani G, Schifini MF, Casciari C, Garinei P. Intermittent versus continuous clodronate administration in postmenopausal women with low bone mass. Bone 2000;26:269-74.

25. Gnudi S, Lisi L, Fini M, Malavolta N. Effect of intramuscular clodronate on bone mass and metabolism in osteoporotic women. Int J Tissue React 2001;23:33-7.

26. Celi M, Balducci S, Schiappoli A, Caliumi C, Petramala $\mathrm{L}$, Cerci $\mathrm{S}$, et al. [The use of parenteral clodronate in elderly women with postmenopausal osteoporosis: compliance, effects on bone mineral density and on bone turnover]. Ann Ital Med Int 2003;18:89-98. Italian.

27. McCloskey E, Selby P, Davies M, Robinson J, Francis RM, Adams J, et al. Clodronate reduces vertebral fracture risk in women with postmenopausal or secondary osteoporosis: results of a double-blind, placebo-controlled 3-year study. J Bone Miner Res 2004;19:728-36.

28. Muscoso E, Puglisi N, Mamazza C, Lo Giudice F, Testai $\mathrm{M}$, Abbate $\mathrm{S}$, et al. Antiresorption therapy and reduction in fracture susceptibility in the osteoporotic elderly patient: open study. Eur Rev Med Pharmacol Sci 2004;8:97-102.

29. Dominguez LJ, Galioto A, Ferlisi A, Alessi MA, Belvedere M, Putignano E, et al. Intermittent intramuscular clodronate therapy: a valuable option for older osteoporotic women. Age Ageing 2005;34:633-6.

30. McCloskey EV, Beneton M, Charlesworth D, Kayan K, deTakats D, Dey A, et al. Clodronate reduces the incidence of fractures in community-dwelling elderly women unselected for osteoporosis: results of a double-blind, placebo-controlled randomized study. J Bone Miner Res 2007;22:135-41.

31. Tanakol R, Yarman S, Bayraktaroglu T, Boztepe H, Alagöl F. Clodronic acid in the treatment of postmenopausal osteoporosis. Clin Drug Investig 2007;27:419-33.

32. Muratore M, Quarta L, Calcagnile F, Quarta E. "Twice-amonth" clodronate $200 \mathrm{mg}$ IM: a new dosing regimen and improved therapy adherence in the treatment of postmenopausal osteoporosis. Adv Ther 2010;27:314-20.

33. Frediani B. Effects of two administration schemes of intramuscular clodronic acid on bone mineral density: a randomized, open-label, parallel-group study. Clin Drug Investig 2011;31:43-50

34. Frediani B, Bertoldi I, Pierguidi S, Nicosia A, Picerno V, Filippou G, et al. Improved efficacy of intramuscular weekly administration of clodronate $200 \mathrm{mg}$ (100 mg twice weekly) compared with $100 \mathrm{mg}$ (once weekly) for increasing bone mineral density in postmenopausal osteoporosis. Clin Drug Investig 2013;33:193-8.

35. Frediani B, Baraldi E, Cremonesi G. Effect of clodronate treatment on risk of fracture: a systematic review and metaanalysis. Calcif Tissue Int 2014;95:295-307.

36. Rizzoli R, Biver E. Glucocorticoid-induced osteoporosis: who to treat with what agent? Nat Rev Rheumato 2015;11:98-109.

37. Rizzoli R, Forni M, Schaad MA, Slosman DO, Sappino AP, Garcia J, et al. Effects of oral clodronate on bone mineral density in patients with relapsing breast cancer. Bone 1996;18:531-7.

38. Saarto T, Blomqvist C, Välimäki M, Mäkelä P, Sarna S, Elomaa I. Clodronate improves bone mineral density in postmenopausal breast cancer patients treated with adjuvant antioestrogens. Br J Cancer 1997; 75:602-5.

39. Saarto T, Blomqvist C, Välimäki M, Mäkelä $P$, Sarna $S$, Elomaa I. Chemical castration induced by adjuvant cyclophosphamide, methotrexate, and fluorouracil chemotherapy causes rapid bone loss that is reduced by clodronate: a randomized study in premenopausal breast cancer patients. J Clin Oncol 1997; 15:1341-7

40. Herrala J, Puolijoki H, Liippo K, Raitio M, Impivaara $\mathrm{O}$, Tala $\mathrm{E}$, et al. Clodronate is effective in preventing corticosteroid-induced bone loss among asthmatic patients. Bone 1998;22:577-82.

41. Muratore M, Santacesaria G, Quarta E, Calcagnile F, Cosentino L, Muratore L. Prevention with clodronate of osteoporosis secondary to inhaled corticosteroid treatment in patients with chronic asthmatic bronchitis. Int J Clin Pharmacol Res 2000;20:61-4.

42. Saarto T, Vehmanen L, Elomaa I, Välimäki M, Mäkelä $\mathrm{P}$, Blomqvist $\mathrm{C}$. The effect of clodronate and antioestrogens on bone loss associated with oestrogen withdrawal in postmenopausal women with breast cancer. $\mathrm{Br} \mathrm{J}$ Cancer 2001;84:1047-51.

43. Vehmanen L, Saarto T, Elomaa I, Mäkelä P, Välimäki M, Blomqvist C. Long-term impact of chemotherapy-induced ovarian failure on bone mineral density (BMD) in premenopausal breast cancer patients. The effect of adjuvant clodronate treatment. Eur J Cancer 2001;37:2373-8.

44. Haderslev KV, Tjellesen L, Sorensen HA, Staun M. Effect of cyclical intravenous clodronate therapy on bone mineral density and markers of bone turnover in patients receiving home parenteral nutrition. Am J Clin Nutr 2002;76:482-8.

45. Frediani B, Falsetti P, Baldi F, Acciai C, Filippou G, Marcolongo R. Effects of 4-year treatment with once-weekly clodronate on prevention of corticosteroid-induced bone loss and fractures in patients with arthritis: evaluation with dualenergy X-ray absorptiometry and quantitative ultrasound. Bone 2003;33:575-81.

46. Vehmanen L, Saarto T, Risteli J, Risteli L, Blomqvist C, Elomaa I. Short-term intermittent intravenous clodronate in the prevention of bone loss related to chemotherapy-induced ovarian failure. Breast Cancer Res Treat 2004;87:181-8.

47. Abitbol V, Briot K, Roux C, Roy C, Seksik P, Charachon A, et al. A double-blind placebo-controlled study of intravenous clodronate for prevention of steroid-induced bone loss in inflammatory bowel disease. Clin Gastroenterol Hepatol 2007;5:1184-9.

48. Rodrigues $\mathrm{P}$, Hering FO, Bruna $\mathrm{P}$, Meller A, Afonso $\mathrm{Y}$. Comparative study of the protective effect of different intravenous bisphosphonates on the decrease in bone mineral density in patients submitted to radical prostatectomy undergoing 


\section{COPYRIGHT $^{\odot} 2018$ EDIZIONI MINERVA MEDICA}

androgen deprivation therapy. A prospective open-label controlled study. Int J Urol 2007; 14:317-20.

49. Saarto T, Vehmanen L, Blomqvist C, Elomaa I. Tenyear follow-up of 3 years of oral adjuvant clodronate therapy shows significant prevention of osteoporosis in early-stage breast cancer. J Clin Oncol 2008;26:4289-95.

50. Tauchmanova L, Guerra E, Pivonello R, De Martino MC, De Leo M, Caggiano F, et al. Weekly clodronate treatment prevents bone loss and vertebral fractures in women with subclinical Cushing's syndrome. J Endocrinol Invest 2009;32:390-4.

51. McCloskey E, Paterson $A$, Kanis J, Tähtelä R, Powles T. Effect of oral clodronate on bone mass, bone turnover and subsequent metastases in women with primary breast cancer. Eur J Cancer 2010;46:558-65.

52. Le Goff B, Heymann D. Pharmacodynamics of bisphosphonates in arthritis. Expert Rev Clin Pharmacol 2011;4:633-41.

53. Hamilton C, Seidner DL. Metabolic bone disease and parenteral nutrition. Curr Gastroenterol Rep 2004;6:335-41.

54. Giusti A. Bisphosphonates in the management of thalassemia-associated osteoporosis: a systematic review of randomised controlled trials. J Bone Miner Metab 2014;32:606-15.

55. Pennisi P, Pizzarelli G, Spina M, Riccobene S, Fiore CE. Quantitative ultrasound of bone and clodronate effects in thalassemia-induced osteoporosis. J Bone Miner Metab 2003;21:402-8.

56. Tolia M, Zygogianni A, Kouvaris JR, Meristoudis C, Margari N, Karakitsos P, et al. The key role of bisphosphonates in the supportive care of cancer patients. Anticancer Res 2014;34:23-37.

57. Mittan D, Lee S, Miller E, Perez RC, Basler JW, Bruder $\mathrm{JM}$. Bone loss following hypogonadism in men with prostate cancer treated with GnRH analogs. J Clin Endocrinol Metab 2002;87:3656-61.

58. Ziaran S, Goncalves FM, Breza JS. Bone mineral density, pathological fractures and bisphosphonate therapy in prostate cancer patients on androgen deprivation therapy. Endocr Regul 2011;45:199-204.

59. Thiryayi WA, Thiryayi SA, Freemont AJ. Histopathological perspective on bone marrow oedema, reactive bone change and haemorrhage. Eur J Radiol 2008;67:62-7.

60. Patel S. Primary bone marrow oedema syndromes. Rheumatology (Oxford) 2014;53:785-92.

61. Henson P, Bruehl S. Complex regional pain syndrome: state of the art update. Curr Treat Options Cardiovasc Med 2010;12:156-67.

62. Varenna M. Bisphosphonates beyond their anti-osteoclastic properties. Rheumatology (Oxford) 2014;53:965-7.

63. Manicourt DH, Brasseur JP, Boutsen Y, Depreseux G, Devogelaer JP. Role of alendronate in therapy for posttraumatic complex regional pain syndrome type I of the lower extremity. Arthritis Rheum 2004;50:3690-7.

64. Breuer B, Pappagallo M, Ongseng F, Chen CI, Goldfarb R. An open-label pilot trial of ibandronate for complex regional pain syndrome. Clin J Pain 2008;24:685-9.

65. Giusti A, Bianchi G. Treatment of complex regional pain syndrome type I with bisphosphonates. RMD Open 2015;1(Suppl 1):e000056.

66. Varenna M, Zucchi F, Ghiringhelli D, Binelli L, Bevilacqua $\mathrm{M}$, Bettica $\mathrm{P}$, et al. Intravenous clodronate in the treatment of reflex sympathetic dystrophy syndrome. A randomized, double blind, placebo controlled study. J Rheumatol 2000;27:1477-83.
67. Muratore M, Calcagnile F, Cosentino L, Serra M, Circhetta C, Quarta E. Il neridronato nel trattamento dell'algodistrofia simpatica riflessa dell'anca, confronto in aperto con il clodronato. Progressi in Reumatologia 2004;5(Suppl. 1):89.

68. Varenna M, Adami S, Rossini M, Gatti D, Idolazzi L, Zucchi F, et al. Treatment of complex regional pain syndrome type I with neridronate: a randomized, double-blind, placebocontrolled study. Rheumatology (Oxford) 2013;52:534-42.

69. Karsdal MA, Bay-Jensen AC, Lories RJ, Abramson S, Spector T, Pastoureau P, et al. The coupling of bone and cartilage turnover in osteoarthritis: opportunities for bone antiresorptives and anabolics as potential treatments? Ann Rheum Dis 2014;73:336-48.

70. Davis AJ, Smith TO, Hing CB, Sofat N. Are bisphosphonates effective in the treatment of osteoarthritis pain? A metaanalysis and systematic review. PLoS One 2013;8:e72714.

71. Rossini M, Viapiana O, Ramonda R, Bianchi G, Olivieri I, Lapadula $\mathrm{G}$, et al. Intra-articular clodronate for the treatment of knee osteoarthritis: dose ranging study vs hyaluronic acid. Rheumatology (Oxford) 2009;48:773-8.

72. Saviola G, Abdi-Ali L, Campostrini L, Sacco S, Baiardi $\mathrm{P}$, Manfredi $\mathrm{M}$, et al. Clodronate and hydroxychloroquine in erosive osteoarthritis: a 24-month open randomized pilot study. Mod Rheumatol 2012;22:256-63.

73. Cocco R, Tofi C, Fioravanti A, Nerucci F, Nannipieri $\mathrm{F}$, Zampieri A, et al. Effects of clodronate on synovial fluid levels of some inflammatory mediators, after intra-articular administration to patients with synovitis secondary to knee osteoarthritis. Boll Soc Ital Biol Sper 1999;75:71-6.

74. Saviola G, Santoro L. [Clodronate in erosive osteoarthrosis of the hand: efficacy for pain and function recovery]. G Ital Med Lav Ergon 2000;22:328-31. Italian.

75. Rossini M, Adami S, Fracassi E, Viapiana O, Orsolini $\mathrm{G}$, Povino MR, et al. Effects of intra-articular clodronate in the treatment of knee osteoarthritis: results of a doubleblind, randomized placebo-controlled trial. Rheumatol Int 2015;35:255-63.

76. Dan D, Germann D, Burki H, Hausner P, Kappeler U, Meyer RP, et al. Bone loss after total hip arthroplasty. Rheumatol Int 2006;26:792-8.

77. Smolders JM, Pakvis DF, Hendrickx BW, Verdonschot N, van Susante JL. Periacetabular bone mineral density changes after resurfacing hip arthroplasty versus conventional total hip arthroplasty. A randomized controlled DEXA study. J Arthroplasty $2013 ; 28: 1177-84$.

78. Molfetta L, Palermo A, Monteforte P, Bianchi G, Pipino F. DEXA analysis of Antega Total Hip Prosthesis. J Orthop Traumatol 2000;1:17-21.

79. Ji WP, Wang XL, Ma MQ, Lan J, Li H. Prevention of early bone loss around the prosthesis by administration of anti-osteoporotic agents and influences of collared and noncollared femoral stem prostheses on early periprosthetic bone loss. Eur J Orthop Surg Traumatol 2013;23:565-71.

80. Nakamura Y, Hayashi K, Abu-Ali S, Naito M, Fotovati A. Effect of preoperative combined treatment with alendronate and calcitriol on fixation of hydroxyapatite-coated implants in ovariectomized rats. J Bone Joint Surg Am 2008;90:824-32.

81. Mochida Y, Bauer TW, Akisue T, Brown PR. Alendronate does not inhibit early bone apposition to hydroxyapatite-coated total joint implants: a preliminary study. J Bone Joint Surg Am 2002;84-A:226-35.

82. Bhandari M, Bajammal S, Guyatt GH, Griffith L, Busse JW, Schünemann $\mathrm{H}$, et al. Effect of bisphosphonates on periprosthetic bone mineral density after total joint arthroplasty. A meta-analysis. J Bone Joint Surg Am 2005;87:293-301.

83. Lin $T$, Yan SG, Cai XZ, Ying ZM. Bisphosphonates 


\section{COPYRIGHT $^{\odot} 2018$ EDIZIONI MINERVA MEDICA}

for periprosthetic bone loss after joint arthroplasty: a metaanalysis of 14 randomized controlled trials. Osteoporos Int 2012;23:1823-34.

84. Arabmotlagh M, Pilz M, Warzecha J, Rauschmann M. Changes of femoral periprosthetic bone mineral density 6 years after treatment with alendronate following total hip arthroplasty. J Orthop Res 2009;27:183-8.

85. Lewis G, Janna S. Alendronate in bone cement: fatigue life degraded by liquid, not by powder. Clin Orthop Relat Res 2006;445:233-8.

86. Hilding M, Ryd L, Toksvig-Larsen S, Aspenberg P. Clodronate prevents prosthetic migration: a randomized radiostereometric study of 50 total knee patients. Acta Orthop Scand 2000;71:553-7.

87. Hilding M, Aspenberg P. Postoperative clodronate decreases prosthetic migration: 4-year follow-up of a randomized radiostereometric study of 50 total knee patients. Acta Orthop 2006;77:912-6.

88. Massari L, De Rito G, Brunoro A, Lo Caputo A, Traina F, Traina GC. Reduction of the periprosthetic bone reabsorbing around uncemented femoral hip implants using Disodium Clodronate: a prospective study with a control group. GIOT 2002;28:79-87.

89. Resch H, Cavalieri L. A randomised double-blind placebo-controlled study to evaluate the efficacy of clodronate in preventing local bone loss after total hip arthroplasty. Clin Cases Miner Bone Metab 2007;4:361.

90. Trevisan C, Ortolani S, Romano P, Isaia G, Agnese L, Dallari D, et al. Decreased periprosthetic bone loss in patients treated with clodronate: a 1-year randomized controlled study. Calcif Tissue Int 2010;86:436-46.

91. Muratore M, Quarta E, Grimaldi A, Calcagnile F, Quarta L. Clinical utility of clodronate in the prevention and management of osteoporosis in patients intolerant of oral bisphosphonates. Drug Des Devel Ther 2011;5:445-54.
92. Miller PD. Chronic kidney disease and the skeleton. Bone Res 2014;2:14044.

93. Diel IJ, Fogelman I, Al-Nawas B, Hoffmeister B, Migliorati C, Gligorov J, et al. Pathophysiology, risk factors and management of bisphosphonate-associated osteonecrosis of the jaw: is there a diverse relationship of amino- and non-aminobisphosphonates? Crit Rev Oncol Hematol 2007;64:198207.

94. Poli G, Mariotti F, Corrado ME, Acerbi D. A tolerability and pharmacokinetic study of a new injectable formulation of disodium clodronate in healthy female volunteers. Eur J Drug Metab Pharmacokinet 2004;29:145-52.

95. Muratore M, Calcagnile F, Serra M, Cosentino L, Quarta E. Efficacia antalgica dei bisfosfonati nella frattura vertebrale di recente insorgenza. Confronto fra clodronato, alendronato e risedronato. Riv It Biol Med 2002;22:55-9.

96. Armingeat T, Brondino R, Pham T, Legré V, Lafforgue P. Intravenous pamidronate for pain relief in recent osteoporotic vertebral compression fracture: a randomized double-blind controlled study. Osteoporos Int 2006;17:1659-65.

97. Laitinen K, Patronen A, Harju P, Löyttyniemi E, Pylkkänen L, Kleimola T, et al. Timing of food intake has a marked effect on the bioavailability of clodronate. Bone 2000;27:293-6.

98. Chesnut $\mathrm{CH}$ 3rd, McClung MR, Ensrud KE, Bell NH, Genant HK, Harris ST, et al. Alendronate treatment of the postmenopausal osteoporotic woman: effect of multiple dosages on bone mass and bone remodeling. Am J Med 1995;99:144-52.

99. Miller PD. Optimizing the management of postmenopausal osteoporosis with bisphosphonates: the emerging role of intermittent therapy. Clin Ther 2005;27:361-76.

100. Åstrand J, Aspenberg P. Reduction of instability-induced bone resorption using bisphosphonates: high doses are needed in rats. Acta Orthop Scand 2002;73:24-30.

Conflicts of interest.-The authors certify that there is no conflict of interest with any financial organization regarding the material discussed in the manuscript.

Authors' contributions. - All authors gave substantial contribution to the conception or design of the article, the selection of articles to be used in this review, the drafting of the article, and the final approval of the version to be published. All authors agree to be accountable for all aspects of the work in ensuring that questions related to the accuracy or integrity of any part of the work are appropriately investigated and resolved.

Acknowledgments.-We thank Dr. Luca Cantini (medical writer) for the preparation of the draft of this article and Chiesi Farmaceutici (Parma, Italy) for funding medical writing activities.

Manuscript accepted: May 8, 2018. - Manuscript received: May 3, 2018. 